\title{
Inhibition Shapes Acoustic Responsiveness in Spherical Bushy Cells
}

\author{
[CChristian Keine and Rudolf Rübsamen \\ Faculty of Biosciences, Pharmacy and Psychology, University of Leipzig, D-04103 Leipzig, Germany
}

\begin{abstract}
Signal processing in the auditory brainstem is based on an interaction of neuronal excitation and inhibition. To date, we have incomplete knowledge of how the dynamic interplay of both contributes to the processing power and temporal characteristics of signal coding. The spherical bushy cells (SBCs) of the anteroventral cochlear nucleus (AVCN) receive their primary excitatory input through auditory nerve fibers via large, axosomatic synaptic terminals called the endbulbs of Held and by additional, acoustically driven inhibitory inputs. SBCs provide the input to downstream nuclei of the brainstem sound source localization circuitry, such as the medial and lateral superior olive, which rely on temporal precise inputs. In this study, we used juxtacellular recordings in anesthetized Mongolian gerbils to assess the effect of acoustically evoked inhibition on the SBCs input- output function and on temporal precision of SBC spiking. Acoustically evoked inhibition proved to be strong enough to suppress action potentials (APs) of SBCs in a stimulus-dependent manner. Inhibition shows slow onset and offset dynamics and increasing strength at higher sound intensities. In addition, inhibition decreases the rising slope of the EPSP and prolongs the EPSP-to-AP transition time. Both effects can be mimicked by iontophoretic application of glycine. Inhibition also improves phase locking of SBC APs to low-frequency tones by acting as a gain control to suppress poorly timed EPSPs from generating postsynaptic APs to maintain precise SBC spiking across sound intensities. The present data suggest that inhibition substantially contributes to the processing power of second-order neurons in the ascending auditory system.
\end{abstract}

Key words: auditory signal processing; cochlear nucleus; in vivo electrophysiology; inhibition; phase locking; spherical bushy cells

\section{Introduction}

The anteroventral cochlear nucleus (AVCN) is part of the first processing station of the central auditory system. Spherical bushy cells (SBCs) located in the rostral pole of the AVCN are constituents of the brainstem sound localization circuitry. These cells receive their main excitatory input directly from auditory nerve fibers (ANFs) by giant synaptic terminals called the endbulbs of Held (Brawer and Morest, 1975; Ryugo and Sento, 1991; Isaacson and Walmsley, 1995; Cao and Oertel, 2010), the activity of which provides suprathreshold excitation (Brawer and Morest, 1975; Schwartz and Gulley, 1978; Ryugo and Sento, 1991; Oertel, 1999; Nicol and Walmsley, 2002). This elaborated axosomatic synaptic terminal provides the condition to simultaneously record in vivo with one and the same electrode the following: (1) the action potentials (APs) of the presynaptic endbulb (prepotential, PP), (2) the EPSPs, and (3) the APs of the SBC (originally termed P, A, and B by Pfeiffer, 1966; Typlt et al., 2010). The different signal components

\footnotetext{
Received Jan. 12, 2015; revised April 23, 2015; accepted April 23, 2015.

Author contributions: C.K. and R.R. designed research; C.K. performed research; C.K. analyzed data; C.K. and R.R. wrote the paper.

This work was supported by the DFG (Grant GRK 1097 to C.K. and Grants RU 390/19-1 and RU 390/20-1 to R.R.). We thank Brett R. Schofield and Thomas Kuenzel for helpful discussions and the two anonymous reviewers whose suggestions substantially improved the manuscript.

The authors declare no competing financial interests.

Correspondence should be addressed to Rudolf Rübsamen, Institute of Biology, University of Leipzig, Talstra $\beta e$ 33, D-04103 Leipzig, Germany. E-mail: rueb@uni-leipzig.de.

DOI:10.1523/JNEUROSCI.0133-15.2015

Copyright $\odot 2015$ the authors $\quad 0270-6474 / 15 / 358579-14 \$ 15.00 / 0$
}

combined form the complex waveforms of the juxtacellularly recorded voltage signals of SBC recordings (Pfeiffer, 1966; Kopp-Scheinpflug et al., 2002; Englitz et al., 2009), which can be used to assess the input-output functions of SBCs under acoustic stimulation (Kuenzel et al., 2011; Nerlich et al., 2014). In addition to the ANF input, SBCs receive acoustically triggered inhibitory input mediated by GABA and/or glycine (Wu and Oertel, 1986; Kolston et al., 1992; Juiz et al., 1996; Mahendrasingam et al., 2004), the function of which is still elusive. The effectiveness of acoustically evoked inhibitory input on SBC responses can be shown by the fact that not all SBCs show monotonic rate-level functions (RLFs), which characterizes their excitatory ANF input (Winter and Palmer, 1991; KoppScheinpflug et al., 2002), and that phase coupling to lowfrequency tone bursts is reduced after the block of inhibitory receptors (Dehmel et al., 2010).

In the present study, juxtacellular in vivo recordings were used to quantify the temporal and level-dependent interplay of acoustically evoked excitation and inhibition in shaping the acoustic responsiveness of SBCs. The results show a twofold effect of inhibition, which acts as a gain control and increases temporal precision of postsynaptic spike generation. The results emphasize that, as in the somatosensory, visual, and olfactory systems, activity of second-order neurons in ascending sensory systems, which establish the basis for a multitude of downstream neuronal processing, must be considered as an interplay of excitation and inhibition. Right from the start, inhibition is an integral part of encoded neuronal information. 


\section{Materials and Methods}

Animals and surgical procedure. All experiments were performed at the Neurobiology Laboratories of the Faculty of Bioscience, Pharmacy and Psychology of the University of Leipzig (Germany), approved by the Saxonian District Government, Leipzig (TVV 06/09), and conducted according to the European Communities Council Directive (86/609/ EEC). Data were collected from 19 subadult Mongolian gerbils (Meriones unguiculatus) of either sex aged postnatal day 25-32 (P25-P32). By choosing this age range, we considered the prolonged postnatal development of inhibitory transmission in auditory brainstem nuclei (Awatramani et al., 2005; Luján et al., 2008; Friauf et al., 2011).

Animals were initially anesthetized by an intraperitoneal injection of a mixture of ketamine hydrochloride ( $140 \mu \mathrm{g} / \mathrm{g}$ body weight, KetaminRatiopharm; Ratiopharm) and xylazine hydrochloride (3 $\mu \mathrm{g} / \mathrm{g}$ body weight, Rompun; Bayer). Supplementary subcutaneous injections of the anesthetic agent at $1 / 3$ of the initial dose were administered approximately every 60-90 min to maintain the animal in an areflexic state. During recording sessions, a feedback-controlled heating pad maintained the animal's body temperature at $36.5-37.5^{\circ} \mathrm{C}$. The animal's skull was exposed along the midsagittal line and a metal head post glued onto the bregma point to fix the animal in the stereotaxic device. The hole for the reference electrode was drilled $1.8-2.0 \mathrm{~mm}$ caudal from the lambda point at the midline and the hole for the recording electrode was drilled $1.5 \mathrm{~mm}$ lateral to the former. The diameters of the holes were 0.5 and $0.8-1.0 \mathrm{~mm}$, respectively. Using this dorsal approach, the recording electrode was lowered into the rostral pole of the AVCN by tilting the animal $12-18^{\circ}$ laterally. Glass micropipettes (GB150F-10; Science Products) were fabricated with a PC-10 vertical puller (Narishige) to have impedances of 1-3 $\mathrm{M} \Omega$ for multiunit recordings and 7-10 $\mathrm{M} \Omega$ for single-unit recordings when filled with $3 \mathrm{M} \mathrm{KCl}$.

Multibarrel recordings. Three-barreled piggyback electrodes (Havey and Caspary, 1980; Dehmel et al., 2010) with the following characteristics were used: tip diameter $4-8 \mu \mathrm{m}$, recordings electrode protruding 15-25 $\mu \mathrm{m}$, impedance 5-12 M $\Omega$ (GB200F-10 and 3GB120F-10; Science Products). Application barrels were filled either with glycine (Sigma-Aldrich, $100 \mathrm{~mm}$, prepared in $20 \mathrm{~mm} \mathrm{NaCl}, \mathrm{pH}$ 6, buffered with 10 mM HEPES), strychnine hydrochloride (Sigma-Aldrich, $2.5 \mathrm{~mm}$, same formula), or just with the carrier (same formula but omitting glycine $\mathrm{HCl}$ and strychnine $\mathrm{HCl}$ ); the latter was used for control experiments. Drugs were applied iontophoretically (EPMS 07; npi electronic) with increasing current steps (drug, +0 to $+40 \mathrm{nA}$; control, +0 to $+100 \mathrm{nA}$ ). Holding current for each barrel was $-15 \mathrm{nA}$ and a channel filled with $1 \mathrm{~m}$ sodium acetate was used for automatic current balancing.

Acoustic stimulation. All recordings were performed in a soundattenuating and electrically isolated chamber (Type 400; Industrial Acoustics) on a vibration-cushioned table. Acoustic stimuli were generated by custom-written MATLAB software (The MathWorks) and digitized at a rate of $97.7 \mathrm{kHz}$. Signals were presented via custom-made earphones (DT770 Pro; beyerdynamic) and delivered through a plastic tube (length $35 \mathrm{~mm}$, diameter $5 \mathrm{~mm}$ ) ending just in front of the eardrum.

Data acquisition. Frequency response areas (FRAs) were obtained by pseudorandom presentation of pure tones $\left(100 \mathrm{~ms}\right.$ in duration, $5 \mathrm{~ms} \cos ^{2}$ ramps, $200 \mathrm{~ms}$ interstimulus interval) derived from a predefined matrix consisting of 20 different frequencies equally spaced on a log scale and 10 different sound pressure levels (SPLs) equally spaced on a linear scale. Each of these 200 frequency/intensity pairs was presented 3-5 times while continuously recording the unit's discharge activity. The FRAs were used to detail each unit's characteristic frequency (CF, the frequency at which the neuron is most sensitive), response thresholds, and, if present, the frequency-intensity domain of an inhibitory sideband.

For in-depth analyses, repetitive stimulations (100 ms duration, $5 \mathrm{~ms}$ $\cos ^{2}$ ramps, $300 \mathrm{~ms}$ interstimulus interval, 200-300 repetitions) were performed at the unit's CF, within the inhibitory sideband, and outside of the receptive field (i.e., spontaneous discharge activity). Stimulation loudness was 20-30 dB SPLs above the respective threshold.

Data analysis. The rostral pole of the AVCN was targeted considering the tonotopic organization of the nucleus described previously (KoppScheinpflug et al., 2002; Dehmel et al., 2010). SBCs were recognized by

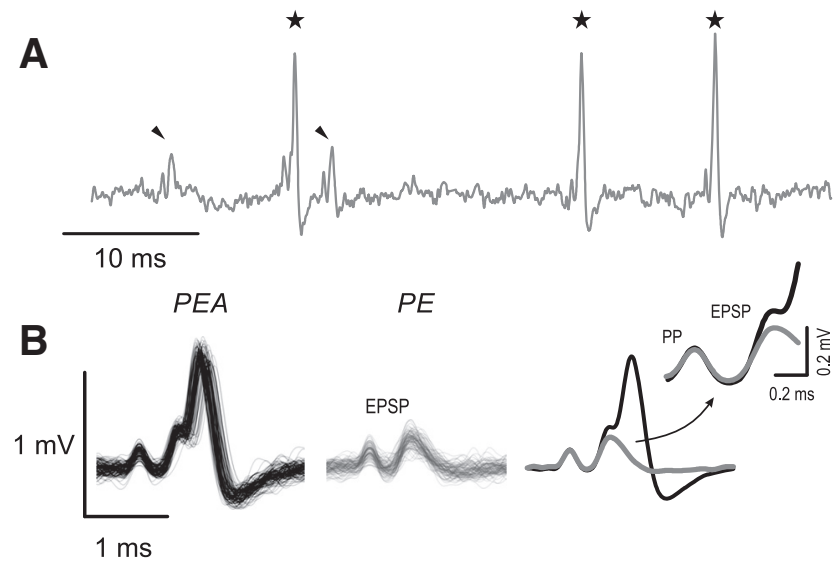

Figure 1. Juxtacellular recordings of SBCs show two types of signals. $\boldsymbol{A}$, Representative voltage trace of an SBC's spontaneous activity displays complex signal waveforms always consisting of a PP and the EPSP, which may (black stars) or may not (black arrowheads) be followed by an AP. B, Superimposed waveforms of 100 single events. Left, PEA composed of PP, EPSP, and AP. Middle, PE composed of PP and EPSP. Both signal complexes originate from the same source, as shown previously by Typlt et al. (2010). Right, The mean signal waveforms suggest that, whereas the PP size stays constant, the EPSP strength is reduced in signals that lack the AP (inset, gray line).

their characteristic complex waveform (Pfeiffer, 1966; Winter and Palmer, 1990; Englitz et al., 2009; Typlt et al., 2010) and their primarylike peristimulus time histogram (PSTH) pattern (Blackburn and Sachs, 1989).

The neurons' voltage signals were preamplified (Neuroprobe 1600; A-M Systems), noise-eliminated (HumBug; Quest Scientific), further amplified (PC1; Tucker-Davis Technologies), and subsequently digitized at a sampling rate of $97.7 \mathrm{kHz}$ (24 bit, RP2.1; Tucker-Davis Technologies). Signals were band-pass filtered between $50 \mathrm{~Hz}$ and $5 \mathrm{kHz}$ using a zero-phase forward and reverse digital IIR filter and stored for offline analysis using custom-written MATLAB software. Recordings were selected for post hoc analysis according to three criteria: (1) SD (AP height)/ mean (AP height) $<20 \%$ (dataset: $10.6 \pm 3.82, n=46$ ), (2) uniformity of voltage signals, and (3) signal-to-noise ratio (AP height divided by SD of the baseline $)>12$ (dataset: $17.8 \pm 5.2, n=46)$.

Juxtacellularly recorded voltage signals of SBCs are typically composed of two (PP-EPSP) or three (PP-EPSP-AP; Fig. 1) components, reflecting the discharge of the PP, the postsynaptic EPSP, and the postsynaptically triggered AP (Englitz et al., 2009; Typlt et al., 2010). Single components were distinguished by means of principal component analysis (Pearson, 1901; Hotelling, 1933) followed by hierarchical clustering. Signals could be grouped into two clusters, one showing the characteristic complex waveform composed of all three components (Fig. $1 A, B$, left) and a second with signals lacking the third component (Fig. $1 A, B$, middle). For reasons of simplicity, the respective signals will be referred to as "PEA" indicating complexes composed of PP-EPSP-AP and "PE" indicating PP-EPSP. For PEA complexes, the inflection point at the rising flank of the second signal component was used to determine the time point of EPSP occurrence by calculating the local minimum of the first derivative preceding the AP maximum. For signals in which the EPSP was temporally separated from the $\mathrm{AP}$, the first local maximum preceding the $\mathrm{AP}$ was taken as the EPSP time point. The EPSP-to-AP transition time was calculated as the time from the occurrence of the EPSP as defined above to the positive peak of the AP component. The average EPSP rising slopes, as related to defined stimulus conditions, were calculated between $20 \%$ and $80 \%$ of the EPSP amplitudes. Durations of APs were calculated as the time between maximum of the AP and the first local minimum thereafter (Sonntag et al., 2011). For the analysis of presynaptic and postsynaptic phase-locking accuracy, we used lowfrequency stimulation and calculated the vector strength (Goldberg and Brown, 1969) separately for the ANF input (i.e., jointly the time points of EPSPs in the PE and PEA complexes), the EPSP, and the AP of PEA complexes. 
A

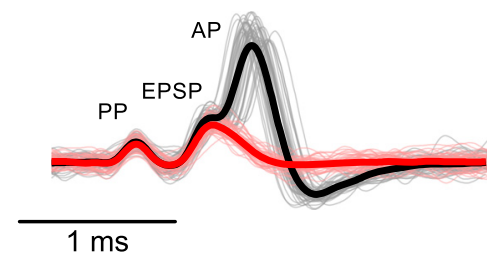

B

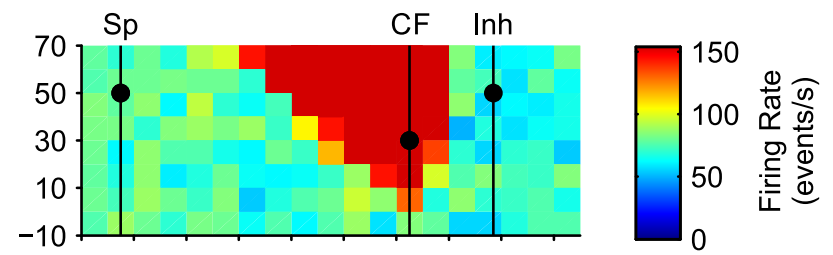

C

D

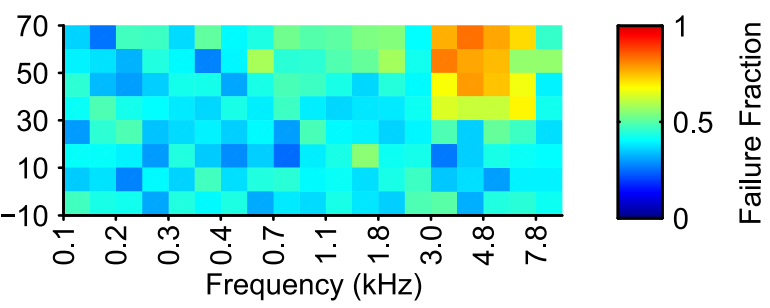

Figure 2. FRAs of auditory nerve input to the $S B C$ and the resulting afferent activity. $A$, Recorded voltage signals were decomposed in PEA (black) and PE (red) with the sum of both indicating the auditory nerve input to the SBC $(\boldsymbol{B})$. The respective FRA showed a v-shaped frequency-intensity domain of excitation (CF: $1.9 \mathrm{kHz}$, threshold: $-3 \mathrm{dBSPL}$ ). C, FRA of the PEA signals of the same SBC showed reduced firing rates both within the excitatory response area (84-154 spikes/s at the highest stimulus intensities and in most parts of the excitatory response area), as well as in frequency-intensity ranges devoid of any discernable impact of stimulation (SP; e.g., mean spike rates $40-56$ spikes/s across the entire intensity range at $0.15 \mathrm{kHz}$ ). In a circumscribed frequency-intensity range on the high-frequency side of the excitatory FRA, acoustic stimulation caused a considerable decrease in PEA even below spontaneous rates, forming an inhibitory sideband. $\boldsymbol{D}$, The decrease in PEA, that is, in postsynaptic firing, went along with a relative increase in $\mathrm{PE}$, that is, the failure fraction, especially in the area of the inhibitory sideband, but to a certain extent also throughout the excitatory FRA.

Statistics. Datasets were tested for Gaussianity and equality of variance using the Shapiro-Wilk test (Shapiro and Wilk, 1965) and Levene's test (Levene, 1960), respectively. Student's $t$ test for independent or dependent samples was applied as appropriate. Aggregated data are reported as mean $\pm \mathrm{SD}$ or median [first quartile, third quartile], respectively. Within-subject comparisons were performed by one-way repeatedmeasures (RM) ANOVA after testing for sphericity using the Mauchly test (Mauchly, 1940) followed by Bonferroni post hoc tests. Cumulative distributions of interevent intervals were compared using the twosample Kolmogorov-Smirnov test. Correlation between quantities were assessed by Spearman's rank correlation (Spearman, 1904) to cover linear and nonlinear relationships. For interpretation of all results, $p<0.05$ was deemed significant. Effect size was calculated using the MES toolbox in MATLAB (Hentschke and Stüttgen, 2011) and reported as $\eta^{2}$ for RM-ANOVA, Cohen's U1 for two-sample comparisons, and most extreme difference (D) for comparisons of cumulative distributions.

\section{Results}

This study aimed to evaluate the effects of acoustically evoked inhibition on excitatory ANF-to-SBC (ANF-SBC) signal transmission in the AVCN. In vivo juxtacellular single-unit recordings
Input Firing

(PE+PEA)

Failure Fraction (PE/[PEA+PE]) were performed while using pure tone stimulation within the unit's high-frequency inhibitory sideband. The response characteristics were compared with the units' spontaneous discharge activity and the activity evoked by acoustic stimulation at the CF. Cells were identified as SBCs based on their characteristic complex voltage signals (Fig. 1), which allowed the discharge of the endbulb of Held (PP) to be differentiated from the EPSP and the postsynaptic AP. Although the PP was always followed by an EPSP, some signal complexes lacked the postsynaptic AP (Fig. 1B; for detailed analysis, see Typlt et al., 2010). This threecomponent distinction is consistent with the P-A-B classification reported previously by Pfeiffer (1966). An additional criterion was the primary-like PSTH, which characterizes SBCs (Rhode et al., 1983; Blackburn and Sachs, 1989; Typlt et al., 2012).

For the stimulation within the inhibitory sideband, we recorded 23 units with low CFs (median [first quartile, third quartile]: 1.77 [1.39, 2.24] kHz, example in Fig. 2, consistent with the predominant location of large, low-CF SBCs in the rostral AVCN (cat: Tolbert et al., 1982; Rouiller and Ryugo, 1984; guinea pig: Hackney et al., 1990; chinchilla: Ostapoff et al., 1994; Monodelphis: Bazwinsky et al., 2008; Mongolian gerbil: Englitz et al., 2009). In the same units, the discharge activity was acquired for stimulation at CF (16/23 units) and outside the receptive field (18/23 units). Another 23 SBCs were recorded $(\mathrm{CF}=1.1 \pm 0.3 \mathrm{kHz})$ to investigate the effect of inhibition on phase locking. On average, cells showed spontaneous firing rates biased toward middle to high frequencies $(49 \pm 17 \mathrm{~Hz})$ and thresholds of $13[6,17] \mathrm{dB}$ SPL.

Units were classified as having inhibitory sidebands when acoustic stimulation outside of the excitatory response area resulted in a significant reduction in the spontaneous firing rate $(p<0.01$, two-sample $t$ test). For the present investigation, we analyzed high-frequency inhibitory sidebands in the range of $4.8[4,5.3] \mathrm{kHz}$ with (inhibitory) thresholds of $42.4 \pm 15.8 \mathrm{~dB}$ SPL (Fig. 2C).

\section{ANF-SBC synapse shows low reliability in vivo}

Each unit's spontaneous activity was acquired for periods of $60-$ $120 \mathrm{~s}$ in the absence of acoustic stimulation. Hierarchical clustering of voltage signals (Fig. 1) yielded two distinct types of signals: PEA (PP-EPSP-AP, Fig. $1 B$ left, black) and PE (PP-EPSP, Fig. $1 B$ middle, gray). In all analyzed cells, this procedure yielded two distinct clusters of these compound signals and no transitional signal complexes in between these two entities. The analysis yielded $97.2-99.2 \%$ of the triggered events to be sorted in either of the two signal categories. The first two components of both complex voltage signals were similar in shape, suggesting that the PE compounds are indicative of signals in which the EPSPs failed to trigger a postsynaptic AP (Fig. $1 B$, middle). The additional 
occurrence of the postsynaptic AP establishes the PEA compound. Based on the observation that both complex signals shared the first two components, their cooccurrence (PE + PEA) was considered the auditory nerve input to the recorded SBC.

In all units, both PE and PEA signals were recorded during spontaneous activity, but their proportion varied greatly between different units. Quantified as failure fraction (PE/[PE + PEA]), the mean incidence of the complex signals lacking APs amounted to $25.8 \pm 12.5 \%$ and varied between $4.5 \%$ and $46.9 \%$. To test for potential presynaptic effects on synaptic transmission reliability, we compared the size of the PPs in PE and PEA signals in units with sufficiently high signal-tonoise ratios to identify the PP clearly $(n=$ 19). The comparison yielded no significant difference in average $\mathrm{PP}$ size $(\mathrm{PE}=$ $0.16 \pm 0.17 \mathrm{mV}$ vs PEA $=0.17 \pm 0.19, p=$ 0.84 , paired $t$ test, $n=19$, $\mathrm{U} 1=0.08$ ), which suggests that postsynaptic spike failures are not likely attributable to the varying convergence of presynaptic inputs (see Discussion for a consideration of this issue). However, EPSPs that triggered APs (PEA) and those that did not (PE) showed discernible differences with respect to the EPSP rising slopes; the average EPSP rising slopes were calculated between $20 \%$ and $80 \%$ of the EPSP amplitudes. According to Kuenzel et al. (2011), this measure is a reliable in vivo estimate of EPSP strength. In the present study, the EPSP slopes were systematically shallower in PE compared with PEA complexes $(\mathrm{PE}=2.06 \pm 0.4 \mathrm{~V} / \mathrm{s}$ vs $\mathrm{PEA}=2.9 \pm 0.7 \mathrm{~V} / \mathrm{s}, p<0.001$, paired $t$ test, $n=23$, $\mathrm{U} 1=0.47$, Fig. $1 B$, right).

\section{Frequency and intensity-specific effects of inhibition}

For each cell, the FRA was analyzed both jointly and separately for the PE and PEA complexes to quantify how acoustically evoked inhibition shapes both the intensity and frequency response profiles of SBCs. The sum of the PE and PEA complexes (Fig. 2A, red and black) was considered the ANF input to the recorded SBC. Figure $2 B$ shows an example of the respective FRA with a mean spontaneous activity of 74 spikes/s, a typical v-shaped area of excitation with a maximum discharge rate of 264 spikes/s at the highest stimulus intensity, and a clearly defined CF at $1.9 \mathrm{kHz}$ with a threshold value of $-3 \mathrm{~dB}$ SPL. The FRA calculated from the PEA complexes, indicating the SBC output signaling, differed considerably with respect to spike rates, as did the frequency and intensity response profiles (Fig. 2C). Spontaneous discharge activity was lower (43.9 spikes/s), as were the spike rates in the excitatory response area (maximum 156.1 spikes/s). Maximum discharge rates were reached at stimulus intensities of $40 \mathrm{~dB}$ SPL and were reduced at higher and lower intensities. The most prominent difference was the occurrence of a coherent frequency-intensity area adjacent to the high-frequency border of the excitatory response area, where SBC spiking was reduced to levels below that for spontaneous activity forming a high- frequency inhibitory sideband. The present analysis focused on units characterized by such inhibitory sidebands, which constitute $\sim 60 \%$ of the low-frequency SBCs (Typlt et al., 2012). In our sample, the reduction in postsynaptic AP firing was most prominent $1.4 \pm 1.1$ octaves above the units' CFs and was always accompanied by a significant increase in the failure fraction (Fig. $2 D ; p<0.001$, one-way RM-ANOVA, Greenhouse-Geisser corrected, $n=23, \eta^{2}=0.83$, spontaneous $=22.1 \pm 13.7 \%$ vs $\mathrm{CF}=$ $45.4 \pm 16.3 \%: p<0.001$; spontaneous vs inhibitory $=67.4 \pm$ $15.3 \%, p<0.001)$.

\section{Effect of inhibition differs across the FRA}

Repetitive acoustic stimulation (100 ms tone bursts, $300 \mathrm{~ms}$ interstimulus intervals, 200-300 repetitions) was used to quantify the dynamics of the units' excitatory and inhibitory responses. As exemplified in Figure 3, acoustic stimulation outside of a unit's receptive field $(0.15 \mathrm{kHz}, 50 \mathrm{~dB}$ SPL; same cell as in Fig. 2, stimulus indicated by dot on "SP" line) did not change the overall input or the incidence of PE or PEA. In the dot raster display in Figure $3 A$, the whole of PE and PEA — symbolized by red and black dots, respectively-shows the input to the SBC, and their uniform distribution indicates that the acoustic stimulation did not change the discharge rate or the proportion between the two signal types. This is illustrated in the top of Figure $3 A$ highlighting stimulus onset and offset. The histogram in Figure $3 B$ shows that the rate of the input to the SBC ( $\mathrm{PE}+\mathrm{PEA}$, gray line) underwent some fluctuations, as did the incidence of SBC APs (black) and AP failures (red), but the rates were not affected by the stimulus. 

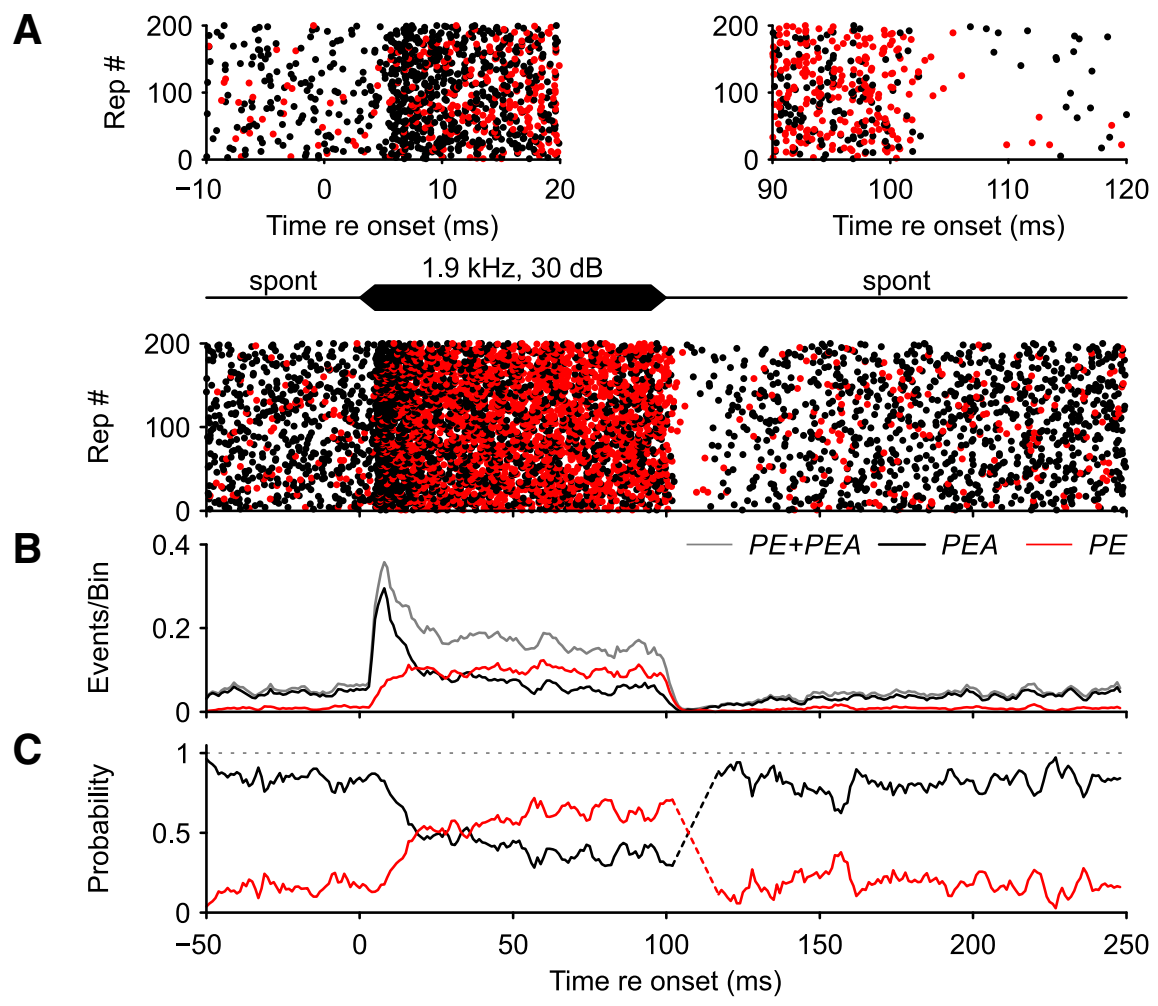

Figure 4. Responses to repetitive acoustic stimulation at unit's CF $1.9 \mathrm{kHz}, 30 \mathrm{dBSPL}$ (marked by dot on the "CF" line Fig. 2). $\boldsymbol{A}$, Dotplot during repetitive (F stimulation. Both PE (red) and PEA (black) signal complexes were present before and after the stimulation. Stimulation at CF resulted in a considerable increase of both signal complexes with increasing incidences of $P E$ with ongoing stimulation. Magnification of the discharge activity at stimulus onset (top, left) and offset (right) at (F stimulation. $\boldsymbol{B}$, Binned data from $\boldsymbol{A}$; binwidth $1 \mathrm{~ms}$, moving average $3 \mathrm{~ms}$. Acoustic stimulation at the unit's $C$ increased the overall input to the SBC (PE + PEA, gray line), as well as SBC spiking (PEA, black line). Both display the typical primary-like response pattern. Although $P E$ modestly increased during the sustained response phase, $P E A$ showed a slight reduction, matched by an increase in $P E$ incidence (red line). C, Probability of PE and PEA normalized to the overall input. Incidence of PE increased gradually with ongoing stimulation and surpassed the AP probability $20 \mathrm{~ms}$ after stimulus onset. Dashed lines indicate bins that contain fewer than five events and therefore probabilities were not calculated.

In addition, normalization of the rates of the two signals to the overall input showed no significant variations (Fig. 3C). During the 200 stimulus repetitions, short-term fluctuations in the incidence of spike failures in the range of $0-0.3$ were observed. However, these instantaneous changes were not correlated with the stimulus onset or offset (Fig. $3 C$ ). To verify that the patterns of occurrence of events is not influenced by acoustic stimulation, we compared the cumulative distribution of interevent intervals (IEIs) during stimulation (5-95 ms) and spontaneous activity $(150-230 \mathrm{~ms})$ and did not find any differences $\left(\mathrm{IEI}_{\text {Spont }}=20 \pm\right.$ $17.2 \mathrm{~ms} \mathrm{vs} \mathrm{IEI}_{\text {Stim }}=18.2 \pm 13.6 \mathrm{~ms}, p=0.65$, two-sample Kolmogorov-Smirnov test, $\mathrm{D}=0.06$ ).

To test the influence of neuronal inhibition on spontaneously occurring spike failures, we recorded from SBCs using piggyback electrodes and applied the glycine antagonist strychnine (2.5 $\mathrm{mM}, \mathrm{pH}$ 6). Although it reliably blocked the effect of coapplied glycine, sole application of strychnine had no effect on either the $\mathrm{AP}$ rate or on the ratio between the overall input $(\mathrm{PE}+\mathrm{PEA})$ and postsynaptic APs (PEA) (data not shown).

Acoustic stimulation at the unit's CF 20-30 dB above the threshold (same cell as in Fig. 2, stimulus indicated by dot on "CF" line) strongly increased the incidence of both PE and PEA (Fig. $4 A$, bottom). It is striking that this stimulation not only triggers a jump in AP rates, but also an increase in the rates of AP failures. The enlargements of the stimulus onset and offset peri- ods elucidate additional response characteristics (Fig. 4A, top) as follows: (1) at the onset of the tone burst, the PEA rates grow faster than the PE rates; (2) PE rates predominate toward the end of the stimulus; and (3) during the period of poststimulus rate depression, both signal types occur, albeit with reduced incidence.

Binning the events in a PSTH emphasizes the dynamics of the respective changes (Fig. $4 B$ ). The overall input to the SBC (Fig. $4 B$, gray line, PE + PEA) and the postsynaptic AP activity (black line, PEA) shows a robust, stimulus-evoked absolute rate increase. Both activities display the primary-like response patterns typical of tone-burst-triggered $\mathrm{ANF}$ and $\mathrm{SBC}$ recordings. In addition, the recordings yielded a pronounced absolute increase in the $\mathrm{PE}$ rate (Fig. $4 B$, red line), indicating that, whereas the acoustically evoked ANF excitation on SBCs is strongly increased, additional physiological processes limit the postsynaptic spike generation. Nevertheless, the increase in postsynaptic APs and AP failures followed very different time courses at stimulus onset. Starting with a delay of $\sim 3 \mathrm{~ms}, \mathrm{PE}+\mathrm{PEA}$ and PEA rates increased steeply to form the characteristic phasic onset of the primary-like response pattern. With a slightly longer delay of $\sim 4 \mathrm{~ms}$, the rates of AP failures (PE) also increased, although with a lower growth rate. This increase in AP failures occurs during the transition phase from the excitatory onset peaks toward the respective sustained response levels (Fig. 4B, gray and black lines). Therefore, the onset peak of the PEA histogram shows a sharper decay than the peak of the input activity. The increase in the AP failure rate continues for $\sim 20$ ms after stimulus onset, outlasting the onset peak of the primary-like PSTH. This is evidenced by normalizing the PE and PEA rates to the SBC input (PE + PEA; Fig. 4C), which shows that CF stimulation caused a substantial increase in AP failures. In the present example (and in 5/16 recorded units), the incidence of AP failures during CF stimulation surpassed the incidence of APs. Significant increases in AP failures during CF stimulation were found in 13/16 recorded SBCs, albeit with different failure rates. During the subsequent sustained phase of the PSTH up to the stimulus offset, a continuous gradual increase in PE probability at the expense of PEA complexes was observed (Fig. 4C). Because of the almost complete poststimulus suppression of neuron spiking, it is difficult to judge the dynamic changes between PE and PEA signals at the stimulus offset (Fig. $4 C$, dashed lines). The recording indicates that $50-100 \mathrm{~ms}$ passed before the unit resumed the prestimulus level of spontaneous activity (Fig. $4 A, B$ ).

An overall assessment of SBC discharge activity during $\mathrm{CF}$ stimulation suggests that, in addition to the strong excitation, other stimulus-triggered physiological mechanisms reduce neuronal spiking. To determine whether postsynaptic depression contributes to the increase in spike failures, the interevent interval distributions were analyzed. A respective reduction would indicate the potential impact of depression. Indeed, during CF 
stimulation, the distribution of interevent intervals of PE signals was shifted toward lower values $\left(\mathrm{IEI}_{\text {Spont }}=20.7 \pm 16 \mathrm{~ms}\right.$ vs $\mathrm{IEI}_{\text {Stim }}=5.5 \pm 3.9 \mathrm{~ms}, p<0.001$, twosample Kolmogorov-Smirnov test, $\mathrm{D}=$ $0.59)$, suggesting that postsynaptic depression contributes to the increase in spike failures. However, the effectiveness of depression in preventing AP spiking was shown to be low compared with that of inhibition (Kuenzel et al., 2015).

As presently shown and also reported by Kuenzel et al. (2011), acoustic stimulation at the unit's CF triggers superposed effects of excitation and inhibition on SBC activity, which made it difficult to draw differentiating conclusions from the above analysis. To dissect the effects of such interactions on the recorded activity, we used pure-tone stimulation within the unit's high-frequency inhibitory sideband ("Inh" in Figs. 2 and 5, which shows the same cell as in Fig. 2). Such stimulation did not change the ANF input to SBCs, as indicated by the overall steady rate of input to the SBC before, during, and after tone burst presentation (PE + PEA; Fig. $5 A$, red and black dots, $B$, gray line) or the interevent intervals $\left(\mathrm{ISI}_{\text {Spont }}=20.6 \pm\right.$ $16.8 \mathrm{~ms} \mathrm{vs} \mathrm{ISI}_{\text {Stim }}=19.6 \pm 15.7 \mathrm{~ms}, p=$ 0.79 , two-sample Kolmogorov-Smirnov test, $\mathrm{D}=0.03$ ). This demonstrates that there was no stimulus-evoked excitatory drive on the SBC, and the observed overall activity can be regarded as the unit's spontaneous discharge activity. Nevertheless, the acoustic stimulation had a prominent effect on SBC activity. It caused an enduring reduction in postsynaptic APs (Fig. $5 A$ ); that is, PE complexes greatly outnumbered PEA complexes after stimulus onset (Fig. 5A, top left), whereas PEAs again prevailed after stimulus offset (Fig. 5A, top right). The histogram shows that PEA reduction is matched with respect to both dimension and temporal dynamics by an increase in PEs (Fig. $5 B, C$ ). For stimulation within the inhibitory sideband compared with CF stimulation, the PEA reduction occurs earlier and proceeds faster. After stimulus offset, the release from reduction lasts for $\sim 10 \mathrm{~ms}$ (Fig. $5 C$ ). Unlike for $\mathrm{CF}$ stimulation, there was neither a general activity-reducing aftereffect of acoustic stimulation nor enduring modifications of the PE/PEA ratio.

To evaluate whether the data of the exemplary unit provides a valid description of the impact of excitatory and inhibitory stimulation on AP reduction in SBC, a summary analysis was performed. For that, the PSTHs for all units recorded under the different stimulus conditions were calculated and averaged across cells (Fig. 6). Similar to the exemplary unit, the activity outside the acoustic response area $(n=18$, indicated as "stimulus 2 oct $<$ CF"), at the units' CFs ( $n=16$, indicated as "CF stimulus"), and within the high-frequency inhibitory sidebands $(n=23$, indicated as "Inh stimulus") were compared. Acoustic stimulation outside of the acoustic response area did not affect the overall input to the SBC [stimulation $(10-90 \mathrm{~ms})=56.1 \pm 15.4 \mathrm{~Hz}$ vs spontaneous $(150-230 \mathrm{~ms})=56.9 \pm 16 \mathrm{~Hz} p=0.34$, paired $t$ test, $\mathrm{U} 1=0.08, n=18$, Fig. $6 A$, top] or the failure fraction
[10-90 ms vs $150-230 \mathrm{~ms}$, stimulation $(10-90 \mathrm{~ms})=25.3 \pm$ $17.3 \%$ vs spontaneous $(150-230 \mathrm{~ms})=25.5 \pm 16.9 \%, p=0.85$, paired $t$ test, $\mathrm{U} 1=0.08, n=18$, Fig. $6 A$, bottom]. Acoustic stimulation at the units' CFs resulted in PSTHs displaying primary-like response patterns of the ANF input to the SBCs [Fig. $6 B$, top, stimulation $(10-90 \mathrm{~ms})=212.4 \pm 75.4 \mathrm{~Hz}$ vs spontaneous $(150-230 \mathrm{~ms})=69.3 \pm 38.7 \mathrm{~Hz}, p<0.001$, paired $t$ test, $\mathrm{U} 1=0.86, n=16$ ], as well as the SBC AP discharges (data not shown). However, the reliability of signal transmission at the ANF-SBC synapse decreased during CF stimulation, as shown by the higher failure fraction with slow onset dynamics [stimulation $(10-90 \mathrm{~ms})=43.3 \pm 17.5 \%$ vs spontaneous $(150-230 \mathrm{~ms})=$ $30.4 \pm 17.5 \%, p<0.01$, paired $t$ test, $\mathrm{U} 1=0.13$, Fig. $6 B$, bottom $]$ and a gradual increase throughout the continuous stimulation (25-90 ms, $\left.r_{\mathrm{s}}=0.57, p<0.001\right)$. When cells were stimulated within their inhibitory sideband, no change in SBC input was observed [stimulation $(10-90 \mathrm{~ms})=68.7 \pm 36.4 \mathrm{~Hz}$ vs spontaneous $(150-230 \mathrm{~ms})=71.2 \pm 39.7, p=0.29, \mathrm{U} 1=0.07$, paired $t$ test, $n=23$, Fig. $6 C$, top]. However, the incidence of AP failures increased considerably and surpassed the probability of AP generation [stimulation $(10-90 \mathrm{~ms})=58.1 \pm 16.8 \%$ vs spontaneous $(150-230 \mathrm{~ms})=26.1 \pm 12.7 \%, p<0.001$, paired $t$ test, $\mathrm{U} 1=0.61, n=23$, Fig. $6 C$, bottom]. The increase in failure fraction showed slow onset and offset dynamics and a decrease with continuing stimulation (25-90 ms, $r_{\mathrm{s}}=-0.57$, $p<0.001)$. 


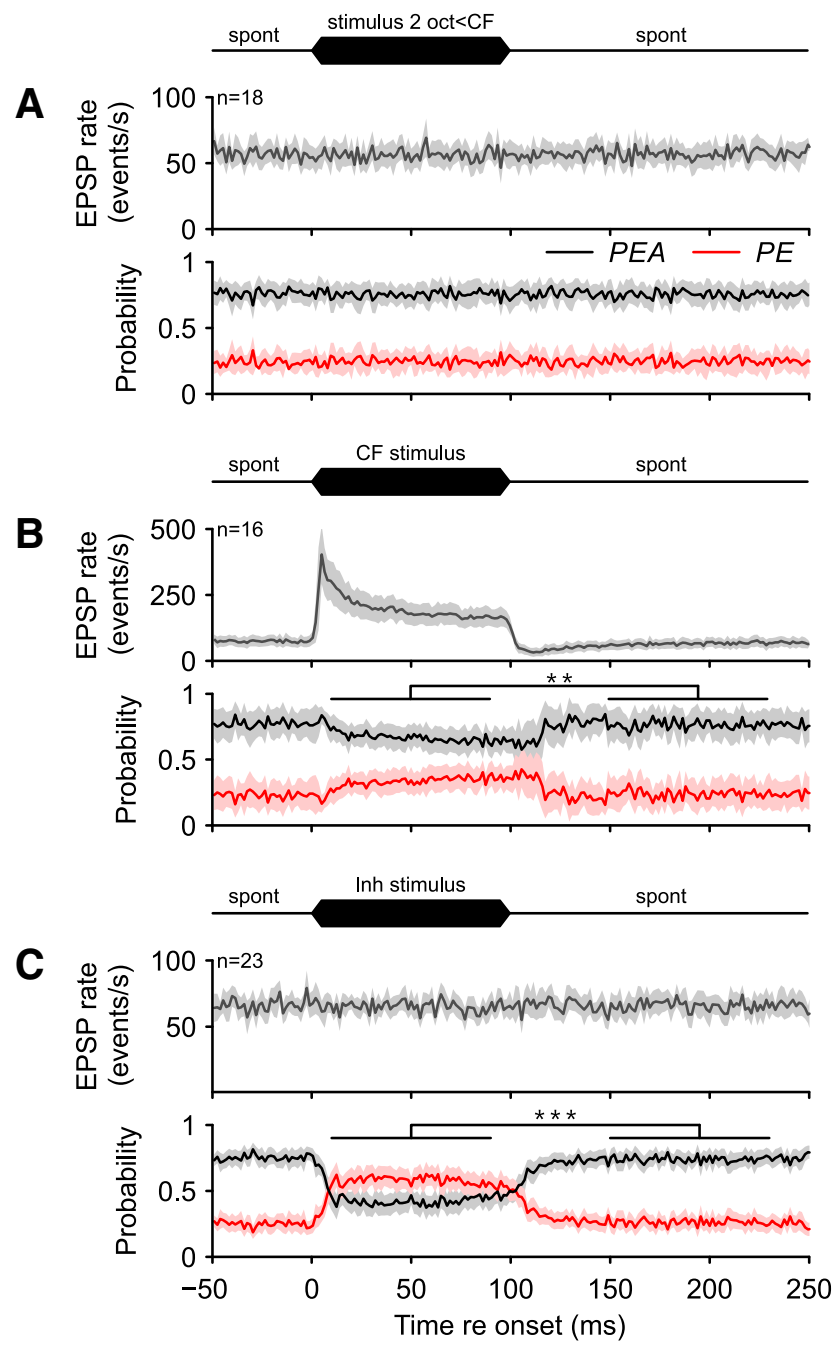

Figure 6. Averaged data of $16-23$ cells. A, Acoustic stimulation ( $100 \mathrm{~ms}$, blackicon on top of the graph) outside of the receptive field did not change the auditory nerve input to the $\operatorname{SBC}(n=$ 18; gray line, top) nor did it alter the proportion between PEA (black line, bottom) and PE (red line). The average failure fraction of about $1 / 4$ was uncorrelated with the acoustic stimulation. $B$, CF stimulation resulted in an excitatory primary-like response pattern of the auditory nerve input (PE) to the SBCs ( $n=16$; gray, top). In the course of excitatory acoustic stimulation, the probability of AP generation (black, bottom) decreased and AP failure fraction increased (red). C, Acoustic stimulation within the inhibitory sideband did not alter the ANF input to the SBCS ( $n=23$; gray, PE + PEA, top), but considerably changed the PE/PEA ratio; the failure fraction increased from $25.3 \%$ to $58.9 \%$ on average. ${ }^{* *} p<0.01,{ }^{* * *} p<0.001$, paired $t$ test.

Inhibition is delayed relative to excitation and persists after stimulation ceases

For an in-depth analysis of the time course of the onset and offset of acoustically evoked excitation and inhibition, PSTH data for all recorded cells were averaged (Fig. 7). The time course of the increase in the AP failure fraction at stimulus onset was compared with the time course of stimulus-evoked AP firing. For the failure fraction, stimulation within the inhibitory sideband showed slow onset dynamics (thin red lines, data from the different units) with an average half-rise time (HRT) of $8.4 \mathrm{~ms}$ (onset of stimulation to $50 \%$ of failure fraction; Fig. 7, bottom left, thick red line). The respective increase in average AP firing triggered by CF stimulation was considerably faster (HRT $=4 \mathrm{~ms}$; Fig. 7 , bottom left, black line). In addition, after the end of the acoustic stimulation, the dynamics of release from inhibition differed considerably from the reduction of CF-triggered AP firing (Fig. 7,
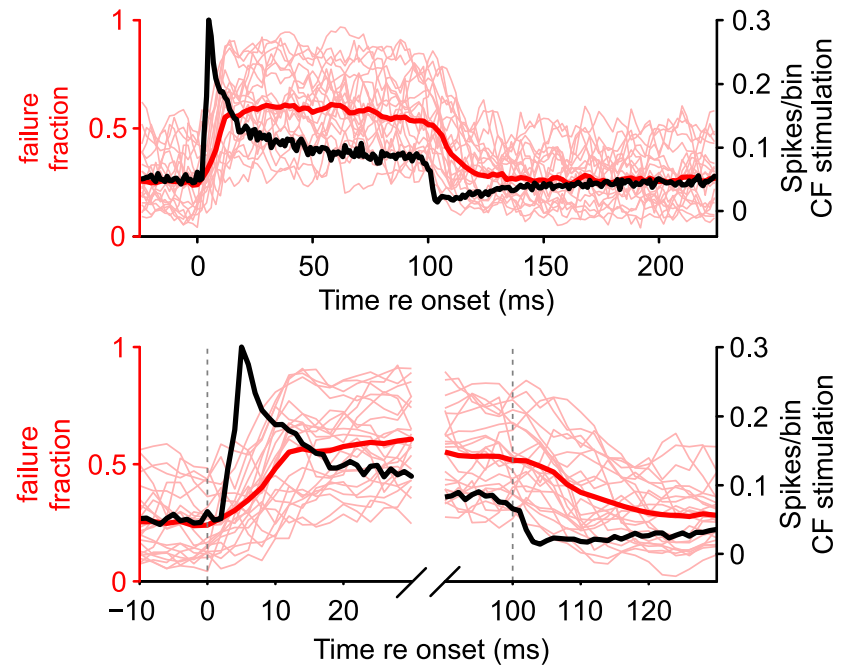

Figure 7. Comparison of onset and offset dynamics of acoustically evoked inhibition and excitation. Mean values (thick red line, $n=23$ ) and failure fractions from individual units (thin red lines) are shown and contrasted with the average AP firing upon (F stimulation (black line, right ordinate, $n=16$ ). Units showed slow inhibitory onset dynamics (bottom left, half-rise time $8.4 \mathrm{~ms}$ ) compared with the faster increase in AP firing during $\mathrm{CF}$ stimulation (black line, HRT $=4 \mathrm{~ms}$ ). After the end of stimulation (bottom right), the failure fraction decayed slower ( $\tau=9.38 \mathrm{~ms}$ ) for stimulation in the inhibitory sideband than AP firing at the offset of CF stimulation ( $\tau=0.86 \mathrm{~ms}$ ).

bottom right). When fitting a mono-exponential function of the form $A \cdot e^{(-x / \tau)}+c$ to the data, the failure fraction showed a 10 -fold slower decay $\left(\tau_{\text {Inh }}=9.38 \mathrm{~ms}, 95 \%\right.$ confidence interval: $[8.9,9.8] \mathrm{ms})$ for the release from inhibition than for the offset of excitation $\left(\tau_{\mathrm{Ex}}=0.86 \mathrm{~ms}, 95 \%\right.$ confidence interval: $\left.[0.67,1.06] \mathrm{ms}\right)$.

\section{Strength of inhibition depends on stimulus intensity}

The auditory system works along five orders of magnitude with respect to intensity, with sound intensity being encoded by the spike rate (Sachs and Abbas, 1974; Palmer and Evans, 1980; Winter et al., 1990). Here, we tested whether the strength of acoustically evoked inhibition also depends directly on sound intensity at the first processing stage of the central auditory system. As done before, we analyzed RLFs under three different conditions: (1) outside of the receptive field, (2) at the CF, and (3) within the inhibitory sideband. Figure $8, A-C$, shows the respective analysis for the exemplary unit shown in Figure 2. Acoustic stimulation outside of the receptive field ("SP," dotted line; see also respective line in Fig. 2) did not change the overall input (PE + PEA; Fig. $8 A$ ) or the AP firing (PEA; Fig. $8 B$ ) of the SBC, resulting in a stable failure fraction (Fig. $8 \mathrm{C}$ ). When stimulating at $\mathrm{CF}$, the overall input rate increased monotonically up to a level of $40 \mathrm{~dB}$ SPL and showed constant firing toward higher SPLs ("CF," solid line, Fig. $8 A$ ). Such monotonicity of the input activity was found in all 23 recordings. However, the RLFs of SBC AP firing differed considerably from the input activity. Of the 23 units, 12 showed pronounced nonmonotonic RLFs, defined as a minimum $20 \%$ decrease of postsynaptic firing at high stimulus levels ("CF" in Fig. $8 B$ for the exemplary unit). Correspondingly, the failure fractions in the units with nonmonotonic RLFs were markedly increased at high stimulus levels (Fig. 8C). For stimulation within the inhibitory sideband, altering the stimulus level did not affect the overall input ("Inh," dashed line, Fig. $8 A$ ), but did result in monotonously decreased SBC firing with increasing stimulation intensity (Fig. 8B), which was accompanied by a steadily increasing failure fraction (Fig. $8 C$ ). All analyzed cells $(n=23)$ showed 
A
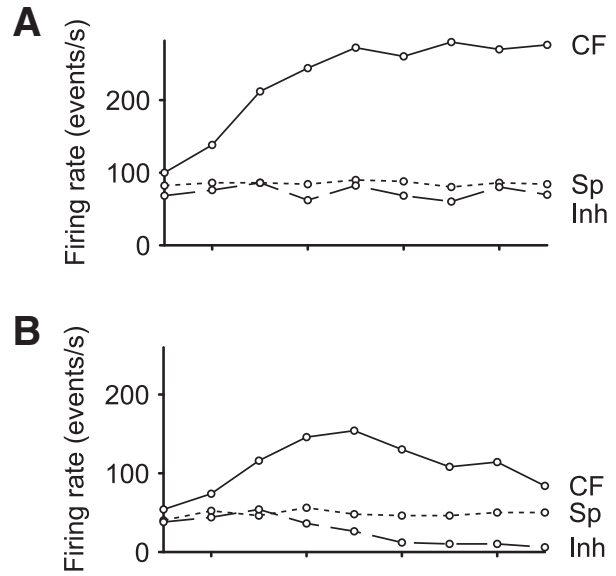

C
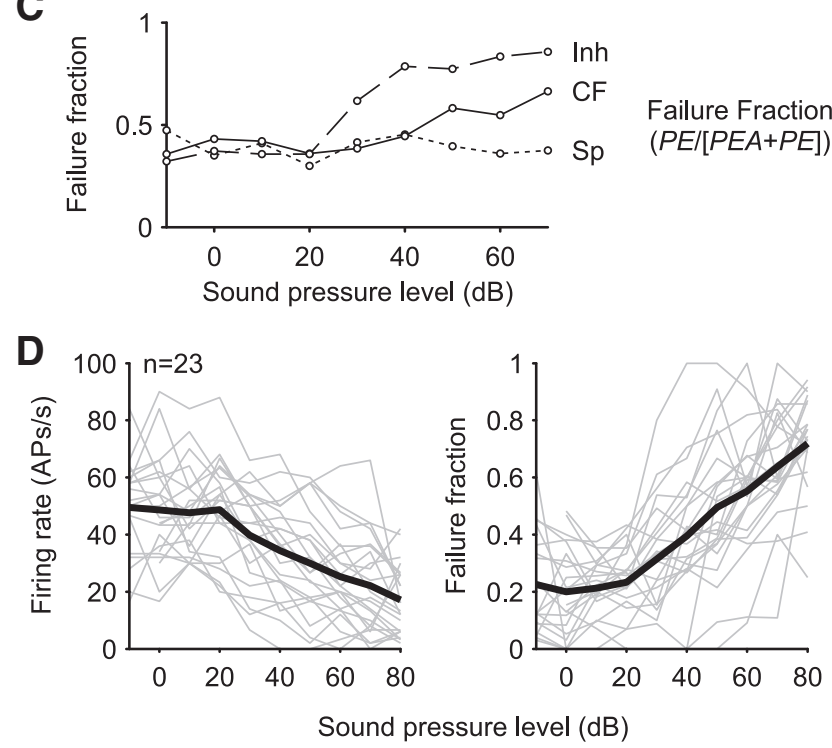

Figure 8. Rate level functions of ANF input and SBC firing at different frequencies (same unit as in Fig. 2). $\boldsymbol{A}$, RLFs of SBC input (PE + PEA) neither showed changes in firing rate outside of the receptive field (short dashed line, "Sp" in Fig. 2) nor for stimulation within the inhibitory sideband (long dashed line; "Inh" in Fig. 2). The firing rate at the unit's (F increased monotonically up to $35 \mathrm{~dB}$ SPL and flattened toward higher SPLs (solid line, "CF" in Fig. 2). B, RLF of AP rates (PEA) showed overall decreased activity for all stimulus conditions. Nevertheless, as for the input activity, the rates did not vary with intensity outside of the unit's response area (short dashed line). At CF, the RLF had a nonmonotonic course (solid line) and stimulation within the inhibitory sideband increasingly reduced rates $>25 \mathrm{dBSPL}$ (long dashed line, "Inh" in Fig. 2). C, Respective failure fractions were calculated as PE/(PE + PEA). The decrease in SBC AP rates compared with the ANF input is accompanied by an increase in failure fraction at $C F$ as well as the inhibitory sideband. Note that for inhibitory sideband stimulation, the increase of failure fraction occurs at lower intensities than that of CF stimulation and the overall effect was larger. $D, S B C$ firing and failure fraction with increasing stimulus intensity at the inhibitory sideband. Data are from 23 units. Units differed in their spontaneous AP rates and failure fraction (gray lines; $0 \mathrm{~dB}$ at left and right). Nevertheless, with increasing stimulus intensity, AP rates decreased (left; mean $r_{\mathrm{s}}=0.7, p<0.001$, black line) and failure fraction increased in all units (right; $r_{\mathrm{s}}=$ $-0.59, p<0.001$, mean: black line).

decreased SBC firing within the inhibitory sideband $(-10$ to $0 \mathrm{~dB}$ $\mathrm{SPL}=48 \pm 16.1 \mathrm{~Hz}$ vs $70-80 \mathrm{~dB} \mathrm{SPL}=18.9 \pm 12 \mathrm{~Hz}, p<0.001$, paired $t$ test, $\mathrm{U} 1=0.61, n=23)$ and a corresponding increase in the failure fraction $(-10$ to $0 \mathrm{~dB}$ SPL $=22.5 \pm 14.2 \mathrm{~Hz}$ vs $70-80$ $\mathrm{dB} \mathrm{SPL}=68 \pm 14.2, p<0.001$, paired $t$ test, $\mathrm{U} 1=0.83, n=23$; Fig. $8 D$ ). The efficiency of acoustically triggered AP inhibition correlated with the level of acoustic stimulation in a unit-specific manner and amounted to spontaneous AP rate reductions by
$19-94 \%$ at a $70-80 \mathrm{~dB}$ SPL tone burst intensity. The absolute increase in failure fraction across units varied between $8 \%$ and $77 \%$ and was negatively correlated with the units' spontaneous failure fraction; that is, units with lower spontaneous failure fractions showed higher absolute increase during inhibitory stimulation $\left(r_{s}=-0.52, p<0.05, n=23\right)$. For stimulation within the inhibitory sideband, both the decrease in SBC firing (Fig. 8D, left) and the increased PE probability (Fig. $8 D$, right) were correlated with the stimulus intensity (APs: $r_{\mathrm{s}}=-0.59, p<0.001$; failure fraction: $r_{\mathrm{s}}=0.7, p<0.001, n=23$ ).

\section{Inhibition reduces EPSP strength and increases EPSP-to-AP transition time}

Previous in vivo studies showed that, within the cochlear nucleus, the duration of juxtacellularly recorded APs can vary between recorded cell types (Mongolian gerbils: Typlt et al., 2012). In addition, the synaptic transmission delay is progressively reduced during early postnatal development (mice: Sonntag et al., 2011), whereas in adults, the transmission delay becomes prolonged with increasing discharge rates (Mongolian gerbils: Tolnai et al., 2009). Here, we tested whether acoustically evoked inhibition also shapes the AP waveform and affects the timing of synaptic transmission. We analyzed APs recorded during spontaneous activity and during inhibitory stimulation. For each recording, $4405 \pm 1767$ APs were analyzed and the relevant parameters could be extracted from $98.7 \pm 1.5 \%$ of all APs. Under both stimulus conditions, the EPSP-AP transition times were similarly correlated with the EPSP rising slopes (spontaneous: $r_{\mathrm{s}}=0.43$, $p<0.001$, inhibitory: $r_{\mathrm{s}}=0.41, p<0.001$, data not shown, but see Kuenzel et al., 2011; Nerlich et al., 2014) while displaying considerable within-unit variability (Fig. 9Ai,Aii). A Boltzmann function of the form $1 /\left(1+e^{-\tau(x-d)}\right)$ was fitted to the cumulative distribution with decay constant $\tau$ and symmetric inflection point $d\left(R^{2}>0.99\right)$. Under acoustically evoked inhibition, the shape of the distribution stayed constant, but the EPSP-AP transition times were shifted toward higher values (Fig. 9Aii). In all cells analyzed, inhibitory stimulation shifted the median EPSP-AP transition time toward higher values (spontaneous = $236 \pm 17 \mu \mathrm{s}$ vs inhibitory $=249 \pm 17 \mu \mathrm{s}, p<0.001$, paired $t$ test, $\mathrm{U} 1=0.28, n=23$, Fig. 9Aiii).

The strength of the EPSPs was estimated by their rising slopes (Fig. 9Bi). Acoustically evoked inhibition reduced EPSP strength and shifted the cumulative distribution toward lower EPSP rising slopes (Fig. 9Bii). This was a small but robust effect observable in $19 / 23$ cells (spontaneous $=2.8 \pm 0.7 \mathrm{~V} / \mathrm{s}$ vs inhibitory $=2.7 \pm$ $0.6 \mathrm{~V} / \mathrm{s}, p<0.001$, paired $t$ test, $\mathrm{U} 1=0.06, n=23$; Fig. 9Biii).

In addition, steeper EPSP rising slopes were correlated with shorter AP durations, both under the conditions of spontaneous activity as well as during acoustic stimulation of inhibition (spontaneous: $r_{\mathrm{s}}=-0.26, p<0.001$; inhibitory: $r_{\mathrm{s}}=-0.27 ; p<0.001$, data not shown). As described above, inhibitory stimulation caused more shallow EPSPs, but under these conditions, the AP durations were still shorter than the respective APs during spontaneous activity (spontaneous $=0.43 \pm 0.07 \mathrm{~ms}$ vs inhibitory $=$ $0.41 \pm 0.06 \mathrm{~ms}, p<0.001$, paired $t$ test, $\mathrm{U} 1=0.04, n=23$ ).

\section{Temporal precision of SBC firing surpasses that of its excitatory input}

Joris and Smith (2008) hypothesized an increase of temporal precision in spike timing from the auditory nerve to bushy cells based on a population comparison of ANF and BC recordings partly mediated by inhibitory inputs. Dehmel et al. (2010) observed a decrease in phase locking when pharmacologically 
$\mathbf{A i}$
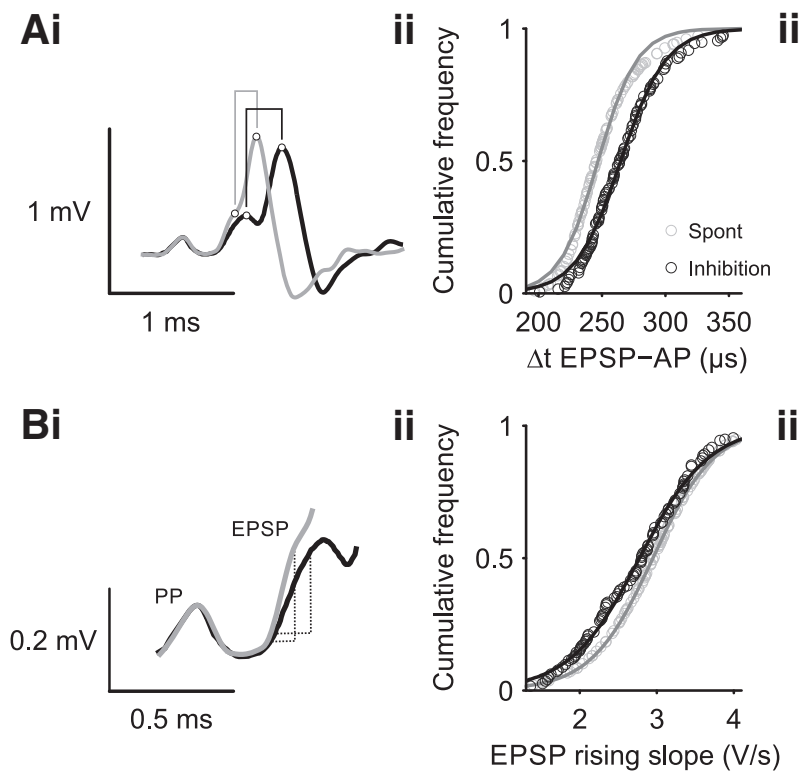

Figure 9. Inhibition flattened EPSP slopes and prolonged EPSP-AP transition times. Ai, Two representative single events with long (black) and short EPSP-AP transition time (gray) aligned at the PP. As indicated in the graph, the analysis quantifies the time from the peak of the EPSP or the respective inflection point of the EPSP rising slope to the peak of the AP. Aii, Representative cumulative distribution function of EPSP-AP transition times for spontaneous activity (light gray) and inhibitory stimulation (dark gray). The shape of the distribution remains unaltered, but inhibitory stimulation shifts the average transition time by $20 \mu s$ (median) toward higher values. Aiii, In all analyzed cells, inhibitory stimulation increased the median EPSP-AP transition time. Bi, Rising slope of EPSP as an indication of EPSP strength. Examples show constant PP signals, but EPSP slopes varying with stimulus condition, spontaneous activity (gray) and inhibitory stimulation (black). Bii, Inhibitory stimulation shifted the cumulative distribution function by $0.16 \mathrm{~V} / \mathrm{s}$ (median) toward lower values, indicating a reduced EPSP strength. Biii, Stimulus evoked reduction in EPSP rising slopes were observed in 19 of 23 cells. $^{* *} p<0.01,{ }^{* * *} p<0.001$.

blocking the inhibition. Here, we aimed at an immediate comparative analysis of phase locking of the SBCs' presynaptic and postsynaptic activity, which is necessary to draw conclusions about the mechanisms that cause these improvements. To determine whether the temporal precision is improved at the level of the SBCs compared with the ANF, we calculated the vector strength during low-frequency stimulation $(0.94 \pm 0.2 \mathrm{kHz}$, $\min =0.5 \mathrm{kHz}, \max =1.2 \mathrm{kHz}, n=23$ ) separately for the following activities: (1) ANF input, that is, EPSP time points in both PE and PEA complexes; (2) the respective EPSP time points of the PEA complexes; and (3) AP time points of the respective signals. Twenty-three units that showed a significant degree of phase locking ( $p<0.001$, Rayleigh test) at the level of the SBC APs were included in the analysis (Fig. 10). The overall analysis shows a highly significant increase in the vector strength from the ANF input to the SBC APs $(p<0.001, \mathrm{RM}-\mathrm{ANOVA}$, GreenhouseGeisser corrected, $\eta^{2}=0.36$, Fig. 10A). The phase locking of the EPSPs differed from that of the APs $\left(\right.$ EPSP $_{\text {succ }}=0.61 \pm 0.07 \mathrm{vs}$ $\mathrm{AP}=0.65 \pm 0.07, p<0.001$, Bonferroni post hoc test, $\mathrm{U} 1=0.34$ ) and furthermore differed depending on whether the EPSPs preceded an $\mathrm{AP}$ or not $\left(\mathrm{EPSP}_{\text {fail }}=0.53 \pm 0.08 \mathrm{vs} \mathrm{EPSP}_{\text {succ }}=0.61 \pm\right.$ $0.07, p<0.001$, Bonferroni post hoc test, $\mathrm{U} 1=0.3)$. Whereas the EPSPs of PE complexes showed a vector strength similar to the ANF input $\left(\mathrm{ANF}=0.51 \pm 0.1 \mathrm{vs} \mathrm{EPSP}_{\text {fail }}=0.53 \pm 0.08, p=0.59\right.$, Bonferroni post hoc test, $\mathrm{U} 1=0.04)$, the temporal precision was substantially increased in EPSPs that triggered an AP (ANF = $0.51 \pm 0.1 \mathrm{vs} \mathrm{EPSP}_{\text {succ }}=0.61 \pm 0.07, p<0.001$, Bonferroni post hoc test, $\mathrm{U} 1=0.41)$. In follow-up analyses, the EPSP rising slope was used as an estimate of the EPSP strength. For each unit, EPSPs were sorted according to their rising slope and the vector strength calculated for large EPSPs (top 20\% of the rising slopes) and small EPSPs (bottom 20\%). Large EPSPs showed a considerably better phase locking than small EPSPs $\left(\mathrm{EPSP}_{\text {small }}=\right.$ $0.56 \pm 0.06$ vs $\mathrm{EPSP}_{\text {large }}=0.62 \pm 0.06$, $p<0.001$, paired $t$ test, $\mathrm{U} 1=0.29, n=23$, data not shown) and are more likely to generate a postsynaptic $\mathrm{AP}\left(\mathrm{P}_{\text {small }}=\right.$ $0.31 \pm 0.23$ vs $\mathrm{P}_{\text {large }}=0.83 \pm 0.11, p<$ 0.001 , paired $t$ test, $\mathrm{U} 1=0.7, n=23$, data not shown). An even greater improvement in phase locking was observed for the $\mathrm{AP}\left(\mathrm{EPSP}_{\text {large }}=0.62 \pm 0.06\right.$ vs $\mathrm{AP}=$ $0.65 \pm 0.07, p<0.001$, Bonferroni post hoc test, $\mathrm{U} 1=0.14, n=23)$. To investigate whether the improvement of AP phase locking can be accounted for by the variability in EPSP-to-AP transmission times, we correlated the latter with the phase position of successful, that is, APpreceding EPSPs. For normalization of the phase angels between units, the maxima of the EPSP histograms were centered around $180^{\circ}$ of the respective stimulus period. In all cells analyzed, the EPSPto-AP transition was negatively correlated to the time point within the stimulus cycle (Fig. 10B, $-0.53<r_{\mathrm{s}}<-0.19, p<$ 0.001); that is, events that occurred early in the cycle had longer EPSP-to-AP transition times than events that occurred later in the cycle. For further analysis, all triggered PEA complexes were split at the median EPSP-to-AP transition time into two groups, one with slower $\left(\right.$ EPSP $_{\text {slow }}$, blue circle, Fig. 10C, inset, same data as in Fig. $10 B)$ and one with faster EPSP-to-AP transition times $\left(\mathrm{EPSP}_{\text {fast }}\right.$,


line) were, on average, triggered earlier in the cycle than events of

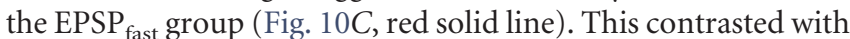
the AP time points in both groups, which showed almost homogeneous distributions (blue and red dashed lines). The distance of the respective distributions EPSP $_{\text {slow }}$ vs $\mathrm{EPSP}_{\text {fast }}$ and $\mathrm{AP}_{\text {slow }} \mathrm{vs}$ $\left.\mathrm{AP}_{\text {fast }}\right)$ was assessed by calculating the Jenson-Shannon distance (Rao, 1982; Wong and You, 1985; Lin and Wong, 1990). In 91.3\% of the recordings (21/23), the JSD between AP groups was smaller than between the respective EPSP groups $\left(\mathrm{JSD}_{\mathrm{EPSP}}=0.015 \pm\right.$ $0.012 \mathrm{vs} \mathrm{JSD}_{\mathrm{AP}}=0.004 \pm 0.006, p<0.001, \mathrm{U} 1=0.09, n=23$, Fig. 10D), suggesting that the variability in EPSP-to-AP transition time facilitates precise SBC spiking.

However, varying EPSP-to-AP transition times can only be functionally linked to precisely phase-locked APs if just EPSPs that are leading the preferred phase are affected. EPSPs lagging behind the preferred phase should be precluded from triggering an AP. To test for this, we analyzed the phase position of PE complexes within the stimulus period relative to the overall ANF input (Fig. 10E). As before, the ANF input was set to be centered on $180^{\circ}$ (PEA + PE, black lines, inset showing period histograms for an exemplary cell). In relation to this distribution, the incidence of PE complexes (Fig. 10E, red lines, see also inset) were shifted to larger phase angles, that is, EPSPs that arrive after the preferred phase are less likely to generate an AP. In all recorded cells, the incidence of PE complexes (Fig. 10E, red lines) was lagging behing the preferred phase of the ANF input (black lines, 
$\mathrm{ANF}=180^{\circ}$ vs $\mathrm{PE}=210 \pm 16^{\circ} p<0.001$, paired $t$ test, $\mathrm{U} 1=0.98, n=23$ ).

We have shown that the effect of inhibition depends on stimulus intensity, which suggests testing whether the improvement of temporal precision is also stimulus dependent, which would provide additional evidence that inhibition has an immediate effect on the quality of phase locking. Indeed, the comparison of phase locking between stimulation at low SPL (5-10 dB above threshold) and at high SPL (40-50 dB above threshold) yielded a substantial improvement in the high-SPL condition (low SPL $=0.03 \pm$ 0.01 vs high $S P L=0.06 \pm 0.02, p<0.001$, paired $t$ test, $\mathrm{U} 1=0.71, n=7$, Fig. $10 F$ ).

\section{Iontophoretic application of glycine resembles the effects of inhibitory stimulation}

In vitro studies suggest a predominant role of glycinergic inhibition in the central auditory system (Moore and Caspary, 1983; Caspary et al., 1994, 2008; Friauf et al., 2011; Nerlich et al., 2014). To evaluate these findings and to test for the impact of glycinergic inhibition in vivo, glycine was applied iontophoretically (100 mM, pH 6) with increasing current steps while recording spontaneous activity of SBCs $(n=6)$. Glycine increased the incidence of PE signals (Fig. 11A, red arrowheads; Fig. $11 B$, red line) and reversibly reduced the number of PEA signals (Fig. $11 A, B$, black stars and black line, respectively, $p<0.001$, RM-ANOVA, GreenhouseGeisser corrected, $\eta^{2}=0.68$, failure fraction: control $=25.9 \pm 18.7 \%$ vs application $=76.1 \pm 20 \%, p<0.001$, control vs recovery $=26.7 \pm 19.2 \%, p=$ $0.79, n=6)$. Nevertheless, the overall EPSP input to the SBC was not changed (Fig. $11 B)\left(p=0.34\right.$, RM-ANOVA, $\eta^{2}=$ 0.04 , control $=69.5 \pm 16.2 \mathrm{~Hz}$ vs application $=66.4 \pm 18 \mathrm{~Hz}, n=6$, data not shown). The increase in failure fraction was directly correlated with the iontophoretic current, reflecting the amount of glycine applied $\left(r_{\mathrm{s}}=0.89, p<0.05\right.$, Fig. $11 C)$. Glycine was potent enough to completely block the postsynaptic activity in all recorded cells when high enough currents were used. Application of the carrier alone $(20 \mathrm{~mm} \mathrm{NaCl}, \mathrm{pH} 6)$ did not affect the input firing rate (control $=$ $71.5 \pm 9.2 \mathrm{~Hz}$ vs application $=72.8 \pm 12.4 \mathrm{~Hz}, p=0.29, \mathrm{RM}-$ ANOVA, $\eta^{2}=0.015, n=6$ ) or the proportion of PE and PEA signals (failure fraction: control $=22.3 \pm 11.3 \%$ vs application $=$ $23.3 \pm 12.6 \%, p=0.32$, RM-ANOVA, $\eta^{2}=0.002, n=6$, data not shown). In addition to affecting the reliability of signal transmission, glycine shaped the remaining APs in a way similar to the changes observed during inhibitory acoustic stimulation (Fig. $11 D)$. The EPSP-AP transition time was prolonged during glycine application (Fig. $11 D$, left, $p<0.001$, RM-ANOVA, $\eta^{2}=$
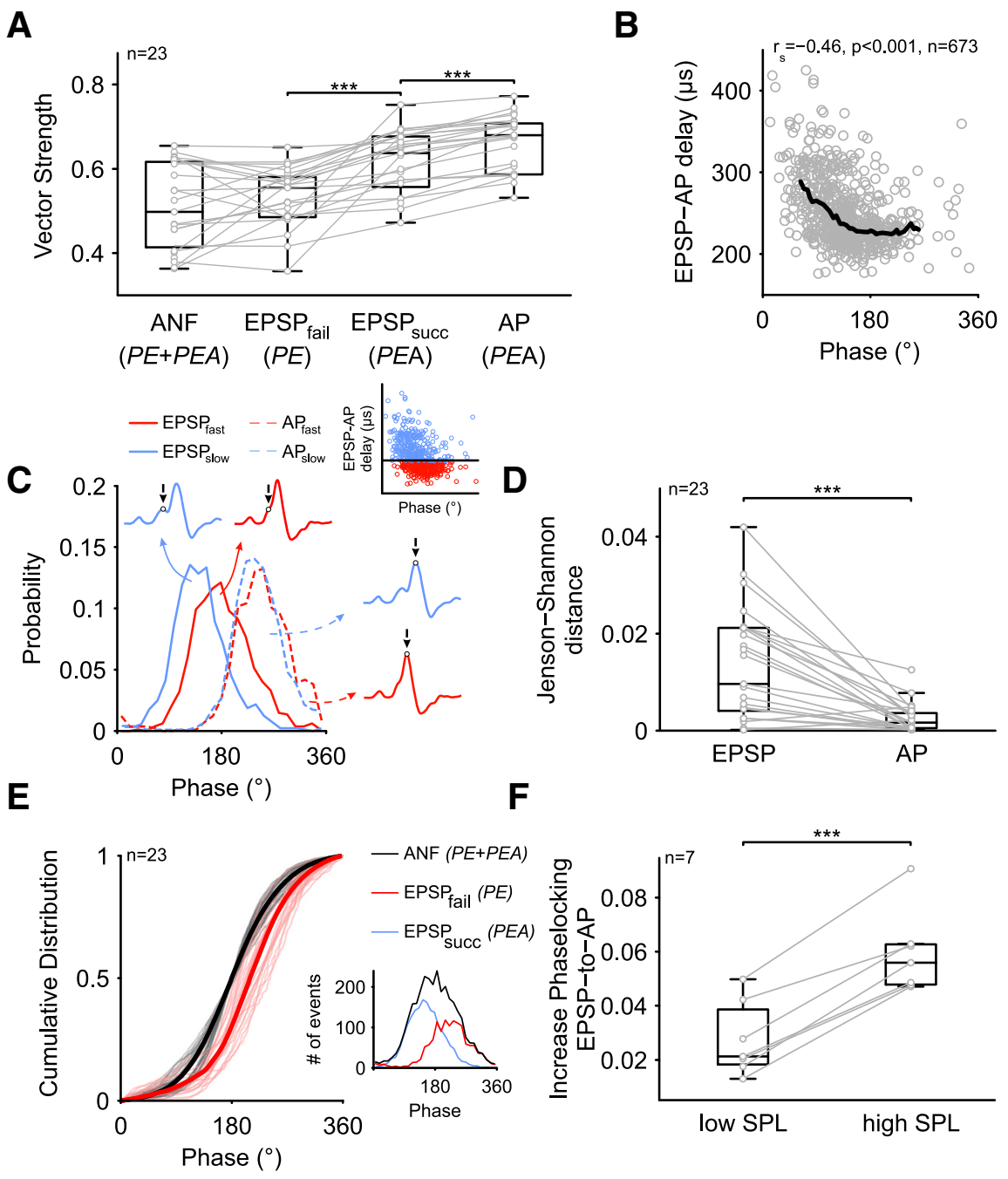

Figure 10. Transformation of phase-locking accuracy in SBCS. A, Vector strength of ANF, EPSPS, and APs for 23 different units. The temporal precision is improved at the level of successful EPSPs and their subsequent APs. B, For PEA complexes, the EPSP-to-AP transition time was negatively correlated with the EPSP time point within the stimulus cycle; that is, signals that occurred early in the phase had longer EPSP-to-AP transition times. The black line represents the median trend line. C, For each recording, the dataset was split at the respective median of EPSP-to-AP transition times to form two groups of PEA complexes, one with slow and one with fast (red) EPSP-to-AP transition times (inset). Although the EPSP time points of events of the EPSP occurred, on average, earlier in the cycle than the ones of the EPSP fast group (solid lines), the time points of the respective APs were much more overlapping (dashed lines). $\boldsymbol{D}$, The divergence of EPSP and AP time points of both groups was assessed by calculating across the two groups. $\boldsymbol{E}$, The period histogram of the ANF input (black) was centered at $180^{\circ}$ and the incidence of PE complexes relative to this position analyzed (red, inset shows exemplary cell). The cumulative distribution of ANF (black, thin lines $=$ single mplexes in all cells lagged the ANF input; that is, EPSPs occurring after the preferred phase are unlikely to generate an AP. $\boldsymbol{F}$, Acoustically stimulation at high SPL ( $40-50 \mathrm{~dB}$ above threshold) resulted in a larger improvement of AP timing than low-SPL stimulation $\left(5-10 \mathrm{~dB}\right.$ above threshold). ${ }^{* * *} p<0.001$.

0.45 , control $=245 \pm 9 \mu$ s vs application $=273 \pm 14 \mu \mathrm{s}, p<$ $0.001, n=6$ ) and the EPSP rising slopes were flattened (Fig. 11D, right, $p<0.01$, RM-ANOVA, $\eta^{2}=0.04$, control $=3.46 \pm 1.03$ $\mathrm{V} / \mathrm{s}$ vs application $=3.1 \pm 0.95 \mathrm{~V} / \mathrm{s}, n=6)$. Both effects were reversible within seconds (EPSP-AP: control vs recovery $=248 \pm$ $10 \mu \mathrm{s}, p=0.61$; EPSP slope: control vs recovery $=3.35 \pm 0.93$ $\mathrm{V} / \mathrm{s}, p=0.64)$ and none of these effects was observed while applying the carrier (20 $\mathrm{mm} \mathrm{NaCl}, \mathrm{pH} 6)$ alone (EPSP-AP transition time: control $=247 \pm 10 \mu \mathrm{s}$ vs application $=250 \pm 9 \mu \mathrm{s}, p=$ 0.47, RM-ANOVA, $\eta^{2}=0.02, n=6$; EPSP slopes: control $=$ $2.98 \pm 1.7 \mathrm{~V} / \mathrm{s}$ vs application $=2.93 \pm 1.4 \mathrm{~V} / \mathrm{s}, p=0.72, \mathrm{RM}-$ ANOVA, $\eta^{2}=0.003, n=6$ ). These data suggest that glycine 
A

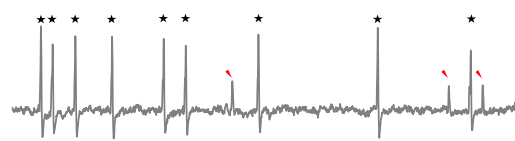

control
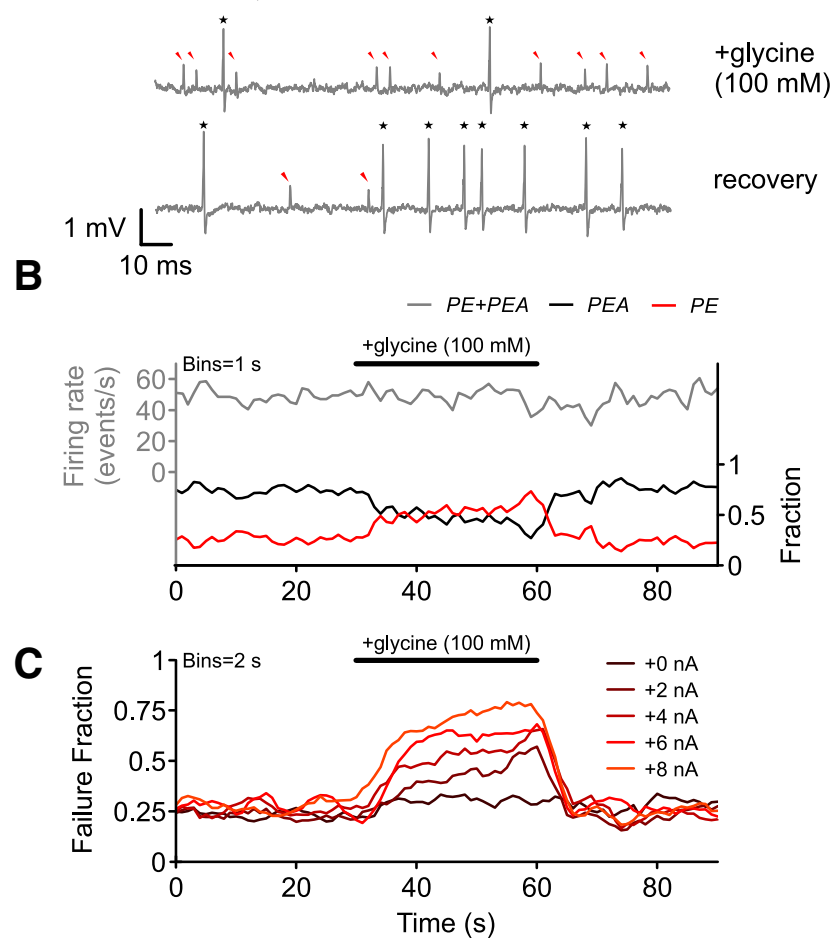

D

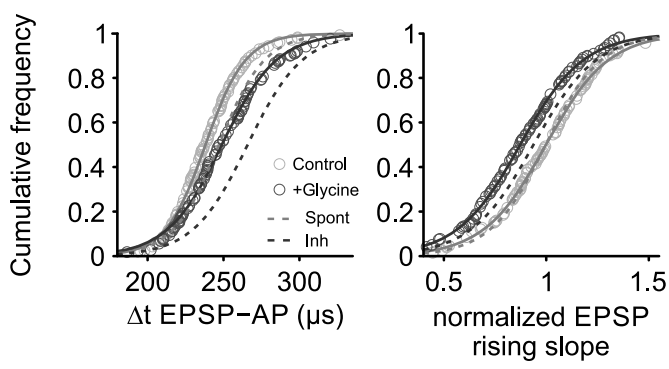

Figure 11. Effect of iontophoretic glycine application on spontaneous activity. A, Both APs (PEA, black star) and PE (red arrowheads) are present under control conditions (top trace). Iontophoretic application of glycine changed the PEAPE ratio; that is, more EPSPs failed to trigger an AP (middle trace). This effect was reversible with the PEA/PE ratio turning back to preapplication conditions (bottom trace). $\boldsymbol{B}$, Binned data from $\boldsymbol{A}$. The overall input rate (PE + PEA, gray line, left ordinate) remained constant during glycine application. The failure fraction (red line, right ordinate) increased during application on the expenses of a decreased AP probability (black line). C, Failure fraction increase upon glycine application was correlated to the iontophoretic current used; that is, the amount of glycine ejected. $\boldsymbol{D}$, Application of glycine did also affect the waveform of remaining APs. Similar to acoustic stimulation, the EPSP-AP transition time was prolonged (left) and the EPSP slopes flattened (right) during application. The magnitude of the effect resembled the inhibitory sideband stimulation. Dashed lines indicate cumulative distribution from Figure $9 B$.

alone can, to a great extent, mimic the effect of acoustically evoked inhibition, which is consistent with the suggested function of glycinergic inhibition reported by in vitro studies.

\section{Discussion}

Earlier in vivo studies analyzed specific features of the juxtacellularly recorded signals to gain insight into the underlying physiological processes of generation of AP discharges and synaptic transmission at giant calyx terminals (Lorteije et al., 2009; Tolnai et al., 2009; Typlt et al., 2010; Kuenzel et al., 2011; Sonntag et al.,
2011). The present study provides a substantiation of the analysis by focusing on the effects of dynamic interrelations between acoustically evoked excitation and inhibition on the generation of APs by SBCs.

The analysis was based on the relation of the different constituents of the neuronal three-component voltage signals under distinctively different input conditions. In addition, dynamic changes in the units' discharge activity were assessed at the respective input conditions, allowing for an analysis of onset and offset of acoustically evoked excitation and inhibition.

\section{SBCs are target of inhibitory inputs}

In addition to excitatory ANF input, SBCs receive inhibitory inputs mediated by GABA and/or glycine (Wu and Oertel, 1986; Kolston et al., 1992; Juiz et al., 1996; Mahendrasingam et al., 2004; Nerlich et al., 2014). Confirming the physiological impact of inhibitory inputs on SBCs, the presence of glycine and GABA receptors have also been reported (Wenthold et al., 1988; Campos et al., 2001). The highest density of inhibitory inputs was found at the rostral pole of the AVCN (Moore and Moore, 1987; Kolston et al., 1992), the primary location of low-frequency SBCs and target area of the present recordings. The impact of inhibition in different SBCs might vary, because this morphologically and physiologically defined class of neurons is the starting point of different afferent processing pathways.

\section{Low reliability of ANF-SBC signal transmission in vivo}

The juxtacellular recordings of SBCs reported here exhibit threecomponent waveforms with a significant number of events lacking the third component. As shown by Typlt et al. (2010), these three components reflect the AP of the endbulb of Held, frequently named "PP"; the EPSP; and the postsynaptic AP, respectively. Without exception, the PPs and the EPSPs occur together (PE), and these signals can be clearly distinguished from the signal complexes additionally followed by the postsynaptic AP (PEA).

These facts allow for an in vivo investigation of SBCs' inputoutput functions using acoustic stimulation (Englitz et al., 2009; Typlt et al., 2010; Kuenzel et al., 2011). The sum of PE and PEA components indicate that the ANF input to the SBC and the characteristics of acoustic responses are in agreement with previous studies in terms of RLF, maximum discharge activity, threshold, and the presence of primary-like PSTH patterns (Schmiedt, 1989; Winter et al., 1990; Ohlemiller et al., 1991; Müller, 1996). The PE complexes taken as such suggest an ANF input that fails to trigger postsynaptic APs, whereas the PEA complexes suggest the input spikes together with the postsynaptic APs. As observed earlier (Pfeiffer, 1966; Englitz et al., 2009; Kuenzel et al., 2011), also in the absence of any acoustic stimulation, the afferent ANF activity does not reliably trigger APs in SBCs. Postsynaptic spike failures were observed in about $1 / 4$ of the signals of a unit and the respective failure rates stayed constant during stimulation outside of the units' acoustic response areas.

There are two possible causes for postsynaptic AP failures: either inhibitory interneurons exert a respective effect and suppress AP generation or SBCs are throughout in a partially depressed state and the excitatory input operates close to the threshold of spike elicitation (Kuenzel et al., 2011; Nerlich et al., 2014). The latter might be due to depletion of readily releasable vesicles and sodium channel inactivation (Azouz and Gray, 2000; Henze and Buzsáki, 2001; Wang and Manis, 2008; Yang and XuFriedman, 2008; Englitz et al., 2009; Platkiewicz and Brette, 2010; Kuenzel et al., 2011). 
We would argue that the major cause of spontaneous spike failures is depression. Our unit sample was biased toward middle to high spontaneous activity and, under these conditions, stochastic fluctuations of the release of excitatory transmitters result in EPSPs, which differ in amplitude, the small ones of which fail to trigger an AP (Wang and Manis, 2008; Yang and Xu-Friedman, 2009; Wang et al., 2010; Kuenzel et al., 2011). Nevertheless, inhibition cannot a priori be ruled out as a cause of spontaneous SBC spike failures, but there are several observations that let it appear an unlikely option. Previously suggested candidates that might provide such inhibition, the AVCN D-stellate cells and tuberculoventral cells of the DCN (Campagnola and Manis, 2014), show low spontaneous discharge activity (Young and Brownell, 1976; Young and Voigt, 1982; Rhode and Smith, 1986; Davis et al., 1996), suggesting that the influence of inhibition will be limited under spontaneous activity. More importantly, local iontophoretic application of strychnine during the recoding of spontaneous activity did not increase the rate of postsynaptic APs directly, indicating that the rate of spontaneous AP discharges is not limited by inhibition.

\section{Effect of inhibition on SBCs acoustically triggered input-output function}

Based on in vivo recordings under the condition of acoustic stimulation, earlier studies reported an impact of GABA and glycine on SBCs' tuning properties (Caspary et al., 1994; Gai and Carney, 2008; Dehmel et al., 2010) and on temporal precision of AP discharges (Dehmel et al., 2010). The effect of inhibition becomes also apparent from the SBCs' nonmonotonic RLFs (Winter and Palmer, 1991; Kopp-Scheinpflug et al., 2002) and from the increase in the precision of AP phase locking to low-frequency tone bursts compared with ANF recordings (Rothman et al., 1993; Joris et al., 1994b; Burkitt and Clark, 1999).

Because ANFs are solely excitatory, the observed inhibitory influence requires the contribution of inhibitory interneurons, possibly from within the $\mathrm{CN}$; for example, $\mathrm{AVCN} \mathrm{D}$-stellate cells and/or tuberculoventral cells of the DCN, which directly or indirectly receive ANF input (Wickesberg and Oertel, 1990; Saint Marie et al., 1991; Campagnola and Manis, 2014). Another possibility would be a back projection from periolivary nuclei; for example, the lateral nucleus of the trapezoid body, which receives input from the AVCN (Smith et al., 1991; Schofield and Cant, 1992). Currently available data do not allow a differentiation between either of these options. However, tuberculoventral cells show onset responses and nonmonotonic RLFs (Rhode, 1999) and D-stellate cells are characterized by transient chopper-onset responses (Oertel et al., 1990; Paolini and Clark, 1999). Therefore, both neuron types within the $\mathrm{CN}$ cannot fully account for the level-dependent, tonic inhibition observed in SBCs in vivo.

The initial characterization of each unit's response areas enabled the establishment of stimulus conditions under which the sole effects of acoustically evoked inhibition could be observed. Setting the stimulus frequency to the units' inhibitory response areas guaranteed a steady (spontaneous) excitatory input and allowed us to quantify the acoustically evoked inhibitory effects on SBC discharges. This is evidenced by the fact that, under these conditions, the overall excitatory input to the SBC (PE + PEA) remained constant before, during, and after the respective toneburst stimulation (Figs. 5, 6). Despite such constant input, the AP rates show a clear stimulus-evoked reduction characterized by delayed onset and offset. These findings are consistent with previous studies showing long latencies of IPSPs in brain slices (Wu and Oertel, 1986) and in vivo (Paolini and Clark, 1998), as well as slow dynamics of IPSCs in SBCs (Xie and Manis, 2013; Nerlich et al., 2014), resulting in a buildup of inhibitory conductance during stimulation.

\section{Increase in temporal precision at the level of the SBCs}

The presently observed increase in phase locking from the ANF to the SBC output is consistent with previous reports (Joris et al., 1994a, 1994b; Paolini et al., 2001; Dehmel et al., 2010; Kuenzel et al., 2011) and similar data have been reported recently for hair cell synapses (Li et al., 2014). Although Kuenzel et al. (2011) reported that the variability in EPSP-to-AP transition time degrades or at best conserves the temporal precision, the present analysis yielded a significant two-step improvement of phase locking at the SBC output: the first by the selection of well timed EPSPs and the second from the shift of the AP toward the preferred stimulus phase. The second step might reflect the involvement of additional non-endbulb excitatory ANF inputs to SBCs, the functional role of which remains elusive (Ryugo and Sento, 1991; Young and Sachs, 2008; Gómez-Nieto and Rubio, 2009; Cao and Oertel, 2010; Lauer et al., 2013). Based on the analysis exemplified in Figure 10, we posit the idea that, in low-frequency SBCs, the input from partially depressed somatic endbulbs (Kuenzel et al., 2011) interacts with dendritic excitatory inputs arising from auditory-nerve branches (Gómez-Nieto and Rubio, 2009). The latter would create phase-locked oscillations of the membrane potential on top of which only well timed endbulb EPSPs are capable of generating a postsynaptic AP (Kuenzel et al., 2015). At higher sound levels, the impact of inhibition also increases, which tightens the condition for AP elicitation, guaranteeing consistent phase locking. Therefore, although slow, this acoustically evoked inhibition might alter dynamically the input-output function and substantially increase the temporal precision in a time-sensitive neuronal circuit.

\section{References}

Awatramani GB, Turecek R, Trussell LO (2005) Staggered development of GABAergic and glycinergic transmission in the MNTB. J Neurophysiol 93:819-828. Medline

Azouz R, Gray CM (2000) Dynamic spike threshold reveals a mechanism for synaptic coincidence detection in cortical neurons in vivo. Proc Natl Acad Sci U S A 97:8110-8115. CrossRef Medline

Bazwinsky I, Härtig W, Rübsamen R (2008) Characterization of cochlear nucleus principal cells of Meriones unguiculatus and Monodelphis domestica by use of calcium-binding protein immunolabeling. J Chem Neuroanat 35:158-174. CrossRef Medline

Blackburn CC, Sachs MB (1989) Classification of unit types in the anteroventral cochlear nucleus: PST histograms and regularity analysis. J Neurophysiol 62:1303-1329. Medline

Brawer JR, Morest DK (1975) Relations between auditory nerve endings and cell types in the cat's anteroventral cochlear nucleus seen with the Golgi method and Nomarski optics. J Comp Neurol 160:491-506. CrossRef Medline

Burkitt AN, Clark GM (1999) Analysis of integrate-and-fire neurons: synchronization of synaptic input and spike output. Neural Comput 11:871901. CrossRef Medline

Campagnola L, Manis PB (2014) A map of functional synaptic connectivity in the mouse anteroventral cochlear nucleus. J Neurosci 34:2214-2230. CrossRef Medline

Campos ML, de Cabo C, Wisden W, Juiz JM, Merlo D (2001) Expression of $\mathrm{GABA}(\mathrm{A})$ receptor subunits in rat brainstem auditory pathways: cochlear nuclei, superior olivary complex and nucleus of the lateral lemniscus. Neuroscience 102:625-638. CrossRef Medline

Cao XJ, Oertel D (2010) Auditory nerve fibers excite targets through synapses that vary in convergence, strength, and short-term plasticity. J Neurophysiol 104:2308-2320. CrossRef Medline

Caspary DM, Backoff PM, Finlayson PG, Palombi PS (1994) Inhibitory inputs modulate discharge rate within frequency receptive fields of anteroventral cochlear nucleus neurons. J Neurophysiol 72:2124-2133. Medline 
Caspary DM, Ling L, Turner JG, Hughes LF (2008) Inhibitory neurotransmission, plasticity and aging in the mammalian central auditory system. J Exp Biol 211:1781-1791. CrossRef Medline

Davis KA, Ding J, Benson TE, Voigt HF (1996) Response properties of units in the dorsal cochlear nucleus of unanesthetized decerebrate gerbil. J Neurophysiol 75:1411-1431. Medline

Dehmel S, Kopp-Scheinpflug C, Weick M, Dörrscheidt GJ, Rübsamen R (2010) Transmission of phase-coupling accuracy from the auditory nerve to spherical bushy cells in the Mongolian gerbil. Hear Res 268:234249. CrossRef Medline

Englitz B, Tolnai S, Typlt M, Jost J, Rübsamen R (2009) Reliability of synaptic transmission at the synapses of Held in vivo under acoustic stimulation. PLoS One 4:e7014. CrossRef Medline

Friauf E, Rust MB, Schulenborg T, Hirtz JJ (2011) Chloride cotransporters, chloride homeostasis, and synaptic inhibition in the developing auditory system. Hear Res 279:96-110. CrossRef Medline

Gai Y, Carney LH (2008) Influence of inhibitory inputs on rate and timing of responses in the anteroventral cochlear nucleus. J Neurophysiol 99: 1077-1095. CrossRef Medline

Goldberg JM, Brown PB (1969) Response of binaural neurons of dog superior olivary complex to dichotic tonal stimuli: some physiological mechanisms of sound localization. J Neurophysiol 32:613-636. Medline

Gómez-Nieto R, Rubio ME (2009) A bushy cell network in the rat ventral cochlear nucleus. J Comp Neurol 516:241-263. CrossRef Medline

Hackney CC, Osen KK, Kolston J (1990) Anatomy and Embryology Anatomy of the cochlear nuclear complex of guinea pig. Anat Embryol 182: 123-149. Medline

Havey DC, Caspary DM (1980) A simple technique for constructing "piggyback" multibarrel microelectrodes. Electroencephalogr Clin Neurophysiol 48:249-251. CrossRef Medline

Hentschke H, Stüttgen MC (2011) Computation of measures of effect size for neuroscience data sets. Eur J Neurosci 34:1887-1894. CrossRef Medline

Henze DA, Buzsáki G (2001) Action potential threshold of hippocampal pyramidal cells in vivo is increased by recent spiking activity. Neuroscience 105:121-130. CrossRef Medline

Hotelling H (1933) Analysis of a complex of statistical variables into principal components. Journal of Educational Psychology 24:417-441. CrossRef

Isaacson JS, Walmsley B (1995) Receptors underlying excitatory synaptic transmission in slices of the rat anteroventral cochlear nucleus. J Neurophysiol 73:964-973. Medline

Joris PX, Smith PH (2008) The volley theory and the spherical cell puzzle. Neuroscience 154:65-76. CrossRef Medline

Joris PX, Carney LH, Smith PH, Yin TC (1994a) Enhancement of neural synchronization in the anteroventral cochlear nucleus. I. Responses to tones at the characteristic frequency. J Neurophysiol 71:1022-1036. Medline

Joris PX, Smith PH, Yin TC (1994b) Enhancement of neural synchronization in the anteroventral cochlear nucleus. II. Responses in the tuning curve tail. J Neurophysiol 71:1037-1051. Medline

Juiz JM, Helfert RH, Bonneau JM, Wenthold RJ, Altschuler RA (1996) Three classes of inhibitory amino acid terminals in the cochlear nucleus of the guinea pig. J Comp Neurol 373:11-26. CrossRef Medline

Kolston J, Osen KK, Hackney CM, Ottersen OP, Storm-Mathisen J (1992) An atlas of glycine- and GABA-like immunoreactivity and colocalization in the cochlear nuclear complex of the guinea pig. Anat Embryol (Berl) 186:443-465. Medline

Kopp-Scheinpflug C, Dehmel S, Dörrscheidt GJ, Rübsamen R (2002) Interaction of excitation and inhibition in anteroventral cochlear nucleus neurons that receive large endbulb synaptic endings. J Neurosci 22:11004-11018. Medline

Kuenzel T, Borst JG, van der Heijden M (2011) Factors controlling the input-output relationship of spherical bushy cells in the gerbil cochlear nucleus. J Neurosci 31:4260-4273. CrossRef Medline

Kuenzel T, Nerlich J, Wagner H, Rübsamen R, Milenkovic I (2015) Inhibitory properties underlying non-monotonic input-output relationship in lowfrequency spherical bushy neurons of the gerbil. Front Neural Circuits 9.

Lauer AM, Connelly CJ, Graham H, Ryugo DK (2013) Morphological characterization of bushy cells and their inputs in the laboratory mouse (Mus musculus) anteroventral cochlear nucleus. PLoS One 8:e73308. CrossRef Medline
Levene H (1960) Robust tests for equality of variances. In: Contributions to probability and statistics (Olkin I, Ghurye SG, Hoeffding W, Madow WG, Mann HB, eds), pp 278-292. Stanford, CA: Stanford University.

Li G-L, Cho S, von Gersdorff H (2014) Phase-locking precision is enhanced by multiquantal release at an auditory hair cell ribbon synapse. Neuron $1-14$.

Lin J, Wong SKM (1990) A new directed divergence measure and its characterization. International Journal of General Systems 17:73-81. CrossRef

Lorteije JA, Rusu SI, Kushmerick C, Borst JG (2009) Reliability and precision of the mouse calyx of Held synapse. J Neurosci 29:13770-13784. CrossRef Medline

Luján R, de Cabo C, Juiz JM (2008) Inhibitory synaptogenesis in the rat anteroventral cochlear nucleus. Neuroscience 154:315-328. CrossRef Medline

Mahendrasingam S, Wallam CA, Polwart A, Hackney CM (2004) An immunogold investigation of the distribution of GABA and glycine in nerve terminals on the somata of spherical bushy cells in the anteroventral cochlear nucleus of guinea pig. Eur J Neurosci 19:993-1004. CrossRef Medline

Mauchly JW (1940) Significance test for sphericity of a normal n-variate distribution. Annals of Mathematical Statistics 11:204-209. CrossRef

Moore JK, Moore RY (1987) Glutamic acid decarboxylase-like immunoreactivity in brainstem auditory nuclei of the rat. J Comp Neurol 260:157174. CrossRef Medline

Moore MJ, Caspary DM (1983) Strychnine blocks binaural inhibition in lateral superior olivary neurons. J Neurosci 3:237-242. Medline

Müller M (1996) The cochlear place-frequency map of the adult and developing Mongolian gerbil. Hear Res 94:148-156. CrossRef Medline

Nerlich J, Kuenzel T, Keine C, Korenic A, Rübsamen R, Milenkovic I (2014) Dynamic fidelity control to the central auditory system: synergistic glycine/GABAergic inhibition in the cochlear nucleus. J Neurosci 34:1160411620. CrossRef Medline

Nicol MJ, Walmsley B (2002) Ultrastructural basis of synaptic transmission between endbulbs of Held and bushy cells in the rat cochlear nucleus. J Physiol 539:713-723. CrossRef Medline

Oertel D (1999) The role of timing in the brain stem auditory nuclei of vertebrates. Annu Rev Physiol 61:497-519. CrossRef Medline

Oertel D, Wu SH, Garb MW, Dizack C (1990) Morphology and physiology of cells in slice preparations of the posteroventral cochlear nucleus of mice. J Comp Neurol 295:136-154. CrossRef Medline

Ohlemiller KK, Echteler SM, Siegel JH (1991) Factors that influence rateversus-intensity relations in single cochlear nerve fibers of the gerbil. J Acoust Soc Am 90:274-287. CrossRef Medline

OstapoffEM, Feng JJ, Morest DK (1994) A physiological and structural study of neuron types in the cochlear nucleus. II. Neuron types and their structural correlation with response properties. J Comp Neurol 346:19-42. CrossRef Medline

Palmer AR, Evans EF (1980) Cochlear fibre rate-intensity functions: no evidence for basilar membrane nonlinearities. Hear Res 2:319-326. CrossRef Medline

Paolini AG, Clark GM (1998) Intracellular responses of the rat anteroventral cochlear nucleus to intracochlear electrical stimulation. Brain Res Bull 46:317-327. CrossRef Medline

Paolini AG, Clark GM (1999) Intracellular responses of onset chopper neurons in the ventral cochlear nucleus to tones: evidence for dualcomponent processing. J Neurophysiol 81:2347-2359. Medline

Paolini AG, FitzGerald JV, Burkitt AN, Clark GM (2001) Temporal processing from the auditory nerve to the medial nucleus of the trapezoid body in the rat. Hear Res 159:101-116. CrossRef Medline

Pearson K (1901) On lines and planes of closest fit to systems of points in space. Philosophical Magazine 2:559-572. CrossRef

Pfeiffer RR (1966) Anteroventral cochlear nucleus: wave forms of extracellularly recorded spike potentials. Science 154:667-668. CrossRef Medline

Platkiewicz J, Brette R (2010) A threshold equation for action potential initiation. PLoS Comput Biol 6:e1000850. CrossRef Medline

Rao C (1982) Diversity: its measurement, decomposition, apportionment and analysis. Sankhya Indian J Stat Ser A 44:1-22.

Rhode WS (1999) Vertical cell responses to sound in cat dorsal cochlear nucleus. J Neurophysiol 82:1019-1032. Medline

Rhode WS, Smith PH (1986) Encoding timing and intensity in the ventral cochlear nucleus of the cat. J Neurophysiol 56:261-286. Medline 
Rhode WS, Oertel D, Smith PH (1983) Physiological response properties of cells labeled intracellularly with horseradish peroxidase in cat ventral cochlear nucleus. J Comp Neurol 213:448-463. CrossRef Medline

Rothman JS, Young ED, Manis PB (1993) Convergence of auditory nerve fibers onto bushy cells in the ventral cochlear nucleus: implications of a computational model. J Neurophysiol 70:2562-2583. Medline

Rouiller EM, Ryugo DK (1984) Intracellular marking of physiologically characterized cells in the ventral cochlear nucleus of the cat. J Comp Neurol 225:167-186. CrossRef Medline

Ryugo DK, Sento S (1991) Synaptic connections of the auditory nerve in cats: relationship between endbulbs of held and spherical bushy cells. J Comp Neurol 305:35-48. CrossRef Medline

Sachs MB, Abbas PJ (1974) Rate versus level functions for auditory-nerve fibers in cats: tone-burst stimuli. J Acoust Soc Am 56:1835-1847. CrossRef Medline

Saint Marie RL, Benson CG, Ostapoff EM, Morest DK (1991) Glycine immunoreactive projections from the dorsal to the anteroventral cochlear nucleus. Hear Res 51:11-28. CrossRef Medline

Schmiedt RA (1989) Spontaneous rates, thresholds and tuning of auditorynerve fibers in the gerbil: comparisons to cat data. Hear Res 42:23-35. CrossRef Medline

Schofield BR, Cant NB (1992) Organization of the superior olivary complex in the guinea pig: II. Patterns of projection from the periolivary nuclei to the inferior colliculus. J Comp Neurol 317:438-455. CrossRef Medline

Schwartz AM, Gulley RL (1978) Non-primary afferents to the principal cells of the rostral anteroventral cochlear nucleus of the guinea pig. Am J Anat 153:489-508. CrossRef Medline

Shapiro S, Wilk M (1965) An analysis of variance test for normality. Biometrika 52:591-611.

Smith PH, Joris PX, Carney LH, Yin TC (1991) Projections of physiologically characterized globular bushy cell axons from the cochlear nucleus of the cat. J Comp Neurol 304:387-407. CrossRef Medline

Sonntag M, Englitz B, Typlt M, Rübsamen R (2011) The calyx of held develops adult-like dynamics and reliability by hearing onset in the mouse in vivo. J Neurosci 31:6699-6709. CrossRef Medline

Spearman C (1904) The proof and measurement of association between two things. American Journal of Psychology 15:72. CrossRef

Tolbert LP, Morest DK, Yurgelun-Todd DA (1982) The neuronal architecture of the anteroventral cochlear nucleus of the cat in the region of the cochlear nerve root: horseradish peroxidase labelling of identified cell types. Neuroscience 7:3031-3052. CrossRef Medline

Tolnai S, Englitz B, Scholbach J, Jost J, Rübsamen R (2009) Spike transmission delay at the calyx of Held in vivo: rate dependence, phenomenological modeling, and relevance for sound localization. J Neurophysiol 102: 1206-1217. CrossRef Medline

Typlt M, Haustein MD, Dietz B, Steinert JR, Witte M, Englitz B, Milenkovic I, Kopp-Scheinpflug C, Forsythe ID, Rübsamen R (2010) Presynaptic and postsynaptic origin of multicomponent extracellular waveforms at the endbulb of Held-spherical bushy cell synapse. Eur J Neurosci 31:15741581. Medline
Typlt M, Englitz B, Sonntag M, Dehmel S, Kopp-Scheinpflug C, Rübsamen R (2012) Multidimensional characterization and differentiation of neurons in the anteroventral cochlear nucleus. PLoS One 7:e29965. CrossRef Medline

Wang Y, Manis PB (2008) Short-term synaptic depression and recovery at the mature mammalian endbulb of Held synapse in mice. J Neurophysiol 100:1255-1264. CrossRef Medline

Wang Y, Ren C, Manis PB (2010) Endbulb synaptic depression within the range of presynaptic spontaneous firing and its impact on the firing reliability of cochlear nucleus bushy neurons. Hear Res 270:101-109. CrossRef Medline

Wenthold RJ, Parakkal MH, Oberdorfer MD, Altschuler RA (1988) Glycine receptor immunoreactivity in the ventral cochlear nucleus of the guinea pig. J Comp Neurol 276:423-435. CrossRef Medline

Wickesberg RE, Oertel D (1990) Delayed, frequency-specific inhibition in the cochlear nuclei of mice: a mechanism for monaural echo suppression. J Neurosci 10:1762-1768. Medline

Winter IM, Palmer AR (1990) Responses of single units in the anteroventral cochlear nucleus of the guinea pig. Hear Res 44:161-178. CrossRef Medline

Winter IM, Palmer AR (1991) Intensity coding in low-frequency auditorynerve fibers of the guinea pig. J Acoust Soc Am 90:1958-1967. CrossRef Medline

Winter IM, Robertson D, Yates GK (1990) Diversity of characteristic frequency rate-intensity functions in guinea pig auditory nerve fibres. Hear Res 45:191-202. CrossRef Medline

Wong AK, You M (1985) Entropy and distance of random graphs with application to structural pattern recognition. IEEE Trans Pattern Anal Mach Intell 7:599-609. Medline

Wu SH, Oertel D (1986) Inhibitory circuitry in the ventral cochlear nucleus is probably mediated by glycine. J Neurosci 6:2691-2706. Medline

Xie R, Manis PB (2013) Target-specific IPSC kinetics promote temporal processing in auditory parallel pathways. J Neurosci 33:1598-1614. CrossRef Medline

Yang H, Xu-Friedman MA (2008) Relative roles of different mechanisms of depression at the mouse endbulb of Held. J Neurophysiol 99:2510-2521. CrossRef Medline

Yang H, Xu-Friedman MA (2009) Impact of synaptic depression on spike timing at the endbulb of Held. J Neurophysiol 102:1699-1710. CrossRef Medline

Young ED, Brownell WE (1976) Responses to tones and noise of single cells in dorsal cochlear nucleus of unanesthetized cats. J Neurophysiol 39:282300. Medline

Young ED, Sachs MB (2008) Auditory nerve inputs to cochlear nucleus neurons studied with cross-correlation. Neuroscience 154:127-138. CrossRef Medline

Young ED, Voigt HF (1982) Response properties of type II and type III units in dorsal cochlear nucleus. Hear Res 6:153-169. CrossRef Medline 